Garcia R, Pilakoutas K, Hajirasouliha I, Guadagnini M, Kyriakides N and Ciupala MA (2015) "Seismic Retrofitting of RC Buildings Using CFRP and PostTensioned Metal Straps: Shake Table Tests", Bulletin of Earthquake Engineering. Final publication available at Springer: http://dx.doi.org/10.1007/s10518-015-9800-8

\title{
Seismic Retrofitting of RC Buildings Using CFRP and Post- Tensioned Metal Straps: Shake Table Tests
}

\author{
Reyes Garcia ${ }^{1 *}$, Kypros Pilakoutas ${ }^{2}$, Iman Hajirasouliha ${ }^{3}$, Maurizio Guadagnini ${ }^{4}$, Nicholas Kyriakides ${ }^{5}$ and \\ Mihaela Anca Ciupala ${ }^{6}$
}

\begin{abstract}
This article examines the effectiveness of two innovative retrofitting solutions at enhancing the seismic behaviour of a substandard reinforced concrete building tested on a shake table as part of the Pan-European funded project BANDIT. To simulate typical substandard construction, the reinforcement of columns and beam-column joints of the full-scale structure had inadequate detailing. An initial series of shake table tests were carried out to assess the seismic behaviour of the bare building and the effectiveness of a first retrofitting intervention using Post-Tensioned Metal Straps. After these tests, columns and joints were repaired and subsequently retrofitted using a retrofitting solution consisting of Carbon Fibre Reinforced Polymers and Post-Tensioned Metal Straps applied on opposite frames of the building. The building was then subjected to unidirectional and three-dimensional incremental seismic excitations to assess the effectiveness of the two retrofitting solutions at improving the global and local building performance. The article provides details of the above shake table testing programme and retrofitting solutions, and discusses the test results in terms of the observed damage, global damage indexes, performance levels and local strains. It is shown that whilst the original bare building was significantly damaged at a peak ground acceleration (PGA) of $0.15 \mathrm{~g}$, the retrofitted building resisted severe threedimensional shake table tests up to $\mathrm{PGA}=0.60 \mathrm{~g}$ without failure. Moreover, the retrofitting intervention enhanced the interstorey drift ratio capacity of the $1^{\text {st }}$ and $2^{\text {nd }}$ floors by $160 \%$ and $110 \%$, respectively. Therefore, the proposed dual retrofitting system is proven to be very effective for improving the seismic performance of substandard buildings.
\end{abstract}

Keywords: Shake Table Tests; Full-scale Buildings; Seismic Retrofitting; CFRP Composites; Post Tensioned Metal Straps; Substandard RC buildings

\footnotetext{
${ }^{1}$ Post-Doctoral Research Associate. Dept. of Civil and Structural Engineering, The University of Sheffield, Sir Frederick Mappin Building, Mappin Street, Sheffield, S1 3JD, UK. Email (corresponding author*): r.garcia@sheffield.ac.uk.

${ }^{2}$ Professor. Dept. of Civil and Structural Engineering, The University of Sheffield, Sir Frederick Mappin Building, Mappin Street, Sheffield, S1 3JD, UK.

${ }^{3}$ Lecturer. Dept. of Civil and Structural Engineering, The University of Sheffield, Sir Frederick Mappin Building, Mappin Street, Sheffield, S1 3JD, UK.

${ }^{4}$ Senior Lecturer. Dept. of Civil and Structural Engineering, The University of Sheffield, Sir Frederick Mappin Building, Mappin Street, Sheffield, S1 3JD, UK.

${ }^{5}$ Post-Doctoral Researcher, Dept. of Civil Engineering and Geomatics, Cyprus University of Technology, 3036, Limassol, Cyprus.

${ }^{6}$ Senior Lecturer, School of Architecture, Computing and Engineering, University of East London, 4-6 University Way, Beckton, London, E16 2RD, UK.
} 


\section{Introduction}

High human and financial losses caused by severe earthquakes (e.g. Kashmir, 2005; China, 2008; Indonesia, 2009; Haiti, 2010; Turkey, 2011; Nepal, 2015) have highlighted the high seismic vulnerability of the existing building stock, much of which comprises non-ductile reinforced concrete $(\mathrm{RC})$ frame buildings built before the introduction of modern seismic design guidelines. The collapse of many of these substandard structures has been frequently attributed to failure of beam-column joints due to inadequate detailing of the joint reinforcement. Different conventional retrofitting techniques have been examined in the past to enhance the performance of substandard joints, such as concrete/shotcrete jacketing (Karayannis et al. 2008; Tsonos 2010; Corazao and Durrani 1989) or steel jacketing/steel plates (Corazao and Durrani 1989; Ghobarah et al. 1996; Biddah et al. 1997). Although the above techniques can be effective at reducing the seismic vulnerability of the current building stock, they can be highly invasive, labour intensive and they usually increase the mass of the building.

In recent years, the use of externally bonded Fibre Reinforced Polymers (FRP) has proven very effective at enhancing the seismic performance of deficient joints (e.g. Antonopoulos and Triantafillou 2003; Ghobarah and El-Amoury 2005; Pantelides and Gergely 2008; Akguzel and Pampanin 2010; Parvin et al. 2010; AlSalloum et al. 2011; Ilki et al. 2011; Sezen 2012). In comparison to the above traditional retrofitting techniques, FRP materials have advantages such as high resistance to corrosion, excellent durability, high strength to weight ratio, and ease and speed of in-situ application (Gdoutos et al. 2000). However, the relatively high initial cost of the FRP materials may prevent its wide use. As a result, alternative retrofitting solutions combining FRP composites with other traditional techniques (e.g. steel jacketing) have been proposed (Ghobarah and ElAmoury 2005; Li et al. 2009; Sasmal et al. 2011). Such 'dual' alternatives can offer effective and attractive solutions for substandard structures, particularly in developing countries where the cost of FRP materials can be considerably higher compared to steel and local labour costs.

Previous research by Frangou et al. (1995) and Frangou (1996) led to the development of a novel technique for retrofitting RC beams and columns using Post-Tensioned Metal Straps (PTMS). The technique uses ductile 
high-strength steel straps post-tensioned around RC elements using pneumatic strapping tools as those used in the packaging industry (see Fig. 1). To maintain the tensioning force after post-tensioning, the strips are fastened mechanically using jaws and push type seals. This provides active confinement to members, thus increasing their ductility and capacity before applying load. Compared to traditional steel/concrete jacketing, PTMS retrofitting has advantages such as ease and speed of application, low material cost and ease of quickly removing/replacing damaged strips and seals. As no adhesives or sophisticated equipment is used, PTMS retrofitting is also expected to provide cost-effective retrofitting solutions due to lower material and labour costs. Experimental research has confirmed the effectiveness of the PTMS technique at enhancing the capacity of columns under compression (Moghaddam et al. 2010), beams with short lap-splices (Helal et al. 2014) and substandard beam-column joints subjected to cyclic load (Helal 2012). More recently, the technique was proven extremely effective at enhancing the seismic behaviour of a full-scale PTMS-retrofitted RC building subjected to low and medium-intensity (up to PGA $=0.35 \mathrm{~g}$ ) shake table tests (Garcia et al. 2014a). However, the behaviour of PTMS-retrofitted structures subjected to severe shaking ( $\mathrm{PGA}>0.40 \mathrm{~g}$ ) still needs to be investigated. Moreover, the potential use of 'dual' retrofitting solutions combining FRP and other alternative techniques has not been examined using full-scale tests. The use of the 'dual' retrofitting strategy can result in more costeffective solutions as only the weaker members of the building are retrofitted with stronger/stiffer FRP composites, whereas stronger members can be retrofitted using innovative inexpensive techniques such as the PTMS.
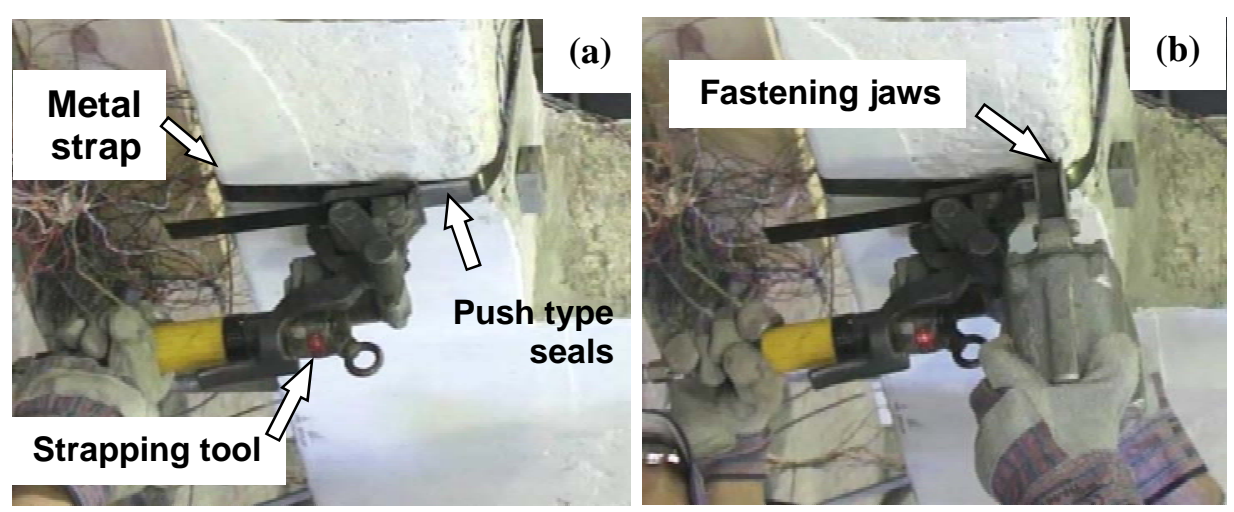

Fig. 1 (a) Post-tensioning and (b) mechanical fastening of straps around an RC member using the PTMS technique 
This article investigates the effectiveness of a 'dual' retrofitting solution using Carbon Fibre Reinforced Polymers (CFRP) and PTMS at improving the performance of a previously damaged full-scale RC building with deficient beam-column joints. The structure was subjected to five Phases of shaking table tests at the CEA/EMSI laboratory facilities (Saclay, France) as part of the EU-funded BANDIT project. The initial shake table tests were reported in Garcia et al. (2014a) and investigated the behaviour of the bare (Phase 1) and PTMS-retrofitted building under low and medium-intensity shaking (Phases 2 and 3 ) of up to PGA $=0.35 \mathrm{~g}$. For the first time, this article presents full details of testing Phases 4 and 5 of the project, where an innovative 'dual' retrofitting solution combining CFRP and PTMS was utilised to retrofit the building. The proposed 'dual' retrofitting solution allowed a direct comparison of the effectiveness of the two techniques using full-scale 3D shaking table tests at high PGA levels (up to PGA=0.60g). The article details the adopted retrofitting strategy, and discusses global and local results from the shake table tests on the retrofitted structure. This study is part of a comprehensive research effort focusing on the seismic retrofitting of substandard RC buildings using PTMS (Garcia et al. 2014a) and FRP composites (Garcia et al. 2014b, 2015).

\section{Experimental programme}

\subsection{Characteristics of tested building}

The geometry of the full-scale two-storey one-bay building was similar to a substandard structure tested previously by the authors (Garcia et al. 2010). The building had a regular plan of $4.26 \times 4.26 \mathrm{~m}$ and a constant floor height of $3.30 \mathrm{~m}$ (Fig. 2a-b). The columns had a cross section of 260×260 (Fig. 2c) and longitudinal column bars of $\varnothing 14 \mathrm{~mm}$ ( $\varnothing$ is the bar diameter). These column bars were lapped over a length $l_{b}=25 \varnothing=350$ $\mathrm{mm}$ just above the $1^{\text {st }}$ floor joints to represent old construction practices, as shown in Fig. $2 \mathrm{~d}$. 


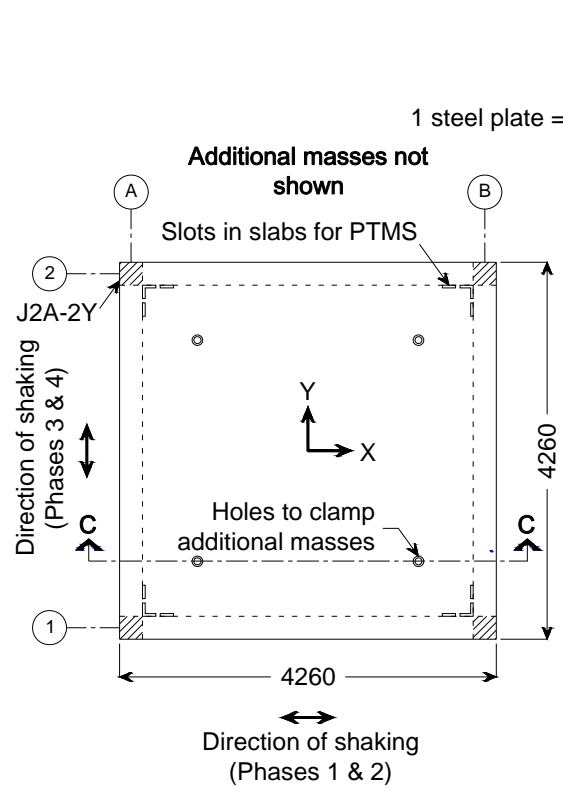

(a) Plan view

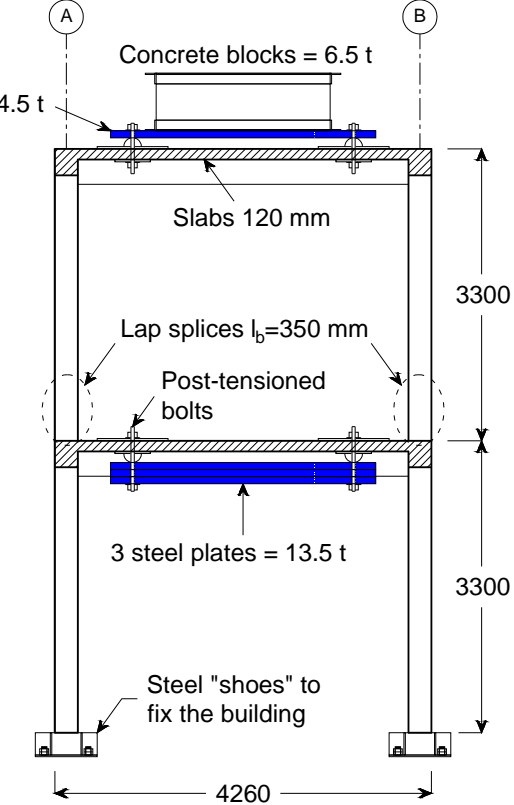

(b) Section C-C

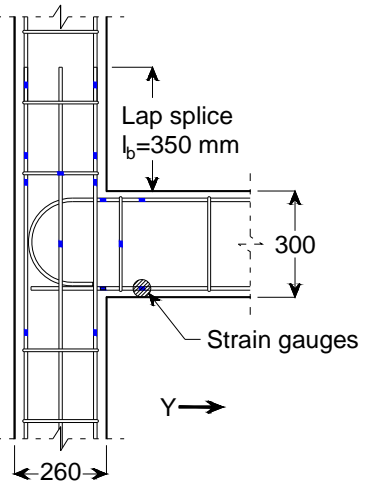

$<260 \rightarrow$
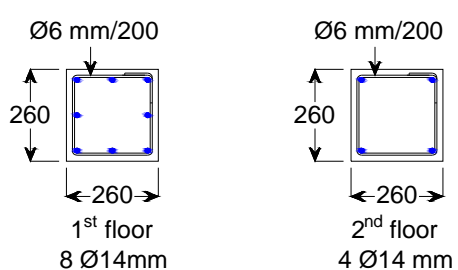

Reinforcement of columns

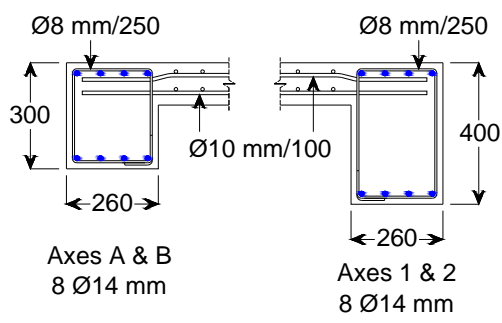

Reinforcement of beams

(c)

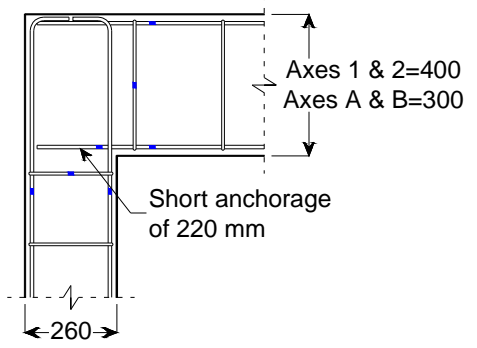

(e) Detailing of $2^{\text {nd }}$ floor joints

(d) Detailing of $1^{\text {st }}$ floor joints

Fig. 2 General geometry and reinforcement detailing of BANDIT building (units: mm), partially adapted from Garcia et al. (2014a)

The beams had a cross section of $260 \times 400 \mathrm{~mm}$ in the $\mathrm{X}$ direction and $260 \times 300 \mathrm{~mm}$ in the $\mathrm{Y}$ direction (see Fig. 2c). The smaller beam depth was selected to increase the flexibility of the building in the Y direction, thus promoting large interstorey drifts (and therefore damage) in such direction during the tests at higher PGA levels. The longitudinal beam reinforcement consisted of $Ø 14 \mathrm{~mm}$ bars. The bottom beam reinforcement was anchored into the joints with no hooks/bends for a length of $220 \mathrm{~mm}$ (approximately 16Ø) to study the effect of deficient bar anchorage, as shown in Fig. 2d. This short anchorage length would be considered insufficient to develop the full capacity of the $\varnothing 14 \mathrm{~mm}$ bars according to Eurocode 2 (EC2) (CEN 2004a). The top beam 
reinforcement of the $1^{\text {st }}$ floor joints was anchored using $90^{\circ}$ bends and U-shaped hooks, which provided adequate anchorage according to EC2 requirements. The top and bottom beam reinforcement was anchored into the $2^{\text {nd }}$ floor joints for $220 \mathrm{~mm}$ in both $\mathrm{X}$ and $\mathrm{Y}$ directions, as shown in Fig. 2e. It should be mentioned that the beam reinforcement at the $2^{\text {nd }}$ floor joints were welded to the longitudinal column reinforcement to repair the building after damage. The column-to-beam relative flexural strength ratio $\left(\Sigma M_{\text {Rcol }} / \Sigma M_{\text {Rbeam }}\right)$ in the bare condition did not satisfy the strong column-weak beam strength philosophy recommended in current seismic design codes. To prevent shear failures outside the joints, the columns were reinforced with $\emptyset 6 \mathrm{~mm}$ stirrups spaced at $200 \mathrm{~mm}$ centres, whereas the beams were reinforced with $\varnothing 8 \mathrm{~mm}$ stirrups spaced at $250 \mathrm{~mm}$ centres. The stirrups were closed with $90^{\circ}$ hooks instead of $135^{\circ}$ hooks typically required by current seismic codes. No confining stirrups were provided in the beam-column joint cores and, therefore, significant damage was expected in these components. The top and bottom of the $120 \mathrm{~mm}$ thick slabs were reinforced with $10 \mathrm{~mm}$ bars spaced at $100 \mathrm{~mm}$ centres in both directions.

The columns and beam-column joints of the building were identified using an ID code according to their location in plan and elevation. The first letter of the ID represents the type of structural member ("C" $=$ column, "J"=joint), while the subsequent digit and letter stand for the axes' intersection at which the member is located in plan. The last digit and letter indicate the floor number and the direction being considered. For instance, the element J2A-2Y corresponds to the beam-column joint of the $2^{\text {nd }}$ floor located at the intersection of axes 2 and A, and parallel to the $\mathrm{Y}$ axis (see Fig. 2a).

\subsection{Construction of specimen and material properties}

The building was cast using two batches of ready-mixed normal-strength concrete, one for each floor. The $1^{\text {st }}$ floor columns were cast on stiff steel "shoe" supports (see Fig. 2b), which were later clamped to the shake table using post-tensioned high-strength bolts to fix the building rigidly. Before casting, rectangular pieces of expanded polystyrene were placed at the locations shown in Fig. 2a to produce vertical slots through the slabs and ease the subsequent installation of the metal straps at beam ends. Four pieces of quarter pipes (radius $=20$ $\mathrm{mm}$ ) were glued to the corners of the columns' formwork to avoid grinding the sharp corners at the retrofitting 
zones. Four plastic pipes were also inserted vertically in each slab formwork to allow the clamping of additional masses (Fig. 2a-b).

After casting, each floor was cured for seven days in the formwork and then kept under standard laboratory conditions. The mean concrete compressive strength $\left(f_{c m}\right)$ and elastic modulus of each batch were determined from tests on nine $160 \times 320 \mathrm{~mm}$ concrete cylinders according to the CPC8 guidelines (RILEM 1994). The indirect tensile splitting strength $\left(f_{c t m}\right)$ was determined from tests on twelve $160 \times 320 \mathrm{~mm}$ cylinders according to EN 12390-6 (CEN 2009b). The modulus of rupture $\left(f_{c f}\right)$ was obtained from four-point bending tests on three $100 \times 100 \times 500 \mathrm{~mm}$ prisms, according to EN 12390-5 (CEN 2009a). All specimens were cast at the same time and cured next to the building. Table 1 summarises the mean values and standard deviations obtained from the tests. It should be noted that whilst some existing substandard RC buildings were built using low-strength concrete $\left(f_{c m}<20 \mathrm{MPa}\right)$, it was impossible to produce such concrete using the equipment available in the testing facilities and the local (high quality) materials used by ready-mix concrete providers. Nonetheless, the strength of the concrete used in this study is representative of typical constructions built during the 1970-80s in the Middle-East, Latin America and Mediterranean regions.

Table 1 Mean mechanical characteristics of concrete mixes used to cast the building

\begin{tabular}{lll}
\hline & $\mathbf{1}^{\text {st }}$ floor & $2^{\text {nd }}$ floor \\
\hline Compressive strength, $f_{c m}(\mathrm{MPa})$ & $30.7(1.56)$ & $24.6(2.03)$ \\
Indirect tensile strength, $f_{c t m}(\mathrm{MPa})$ & $2.67(0.38)$ & $2.28(0.22)$ \\
Flexural strength, $f_{c f m}(\mathrm{MPa})$ & $3.60(0.26)$ & $3.83(0.32)$ \\
Elastic modulus, $E_{c m}(\mathrm{GPa})$ & $24.3(1.30)$ & $21.2(1.16)$ \\
\hline
\end{tabular}

Note: standard deviations shown in parentheses

Due to difficulties in finding low-strength plain bars, the building was reinforced using ribbed bars grade S500 complying with NF A 35-016-1 (AFNOR 2007). In comparison to low-strength bars, the use of such reinforcement is more critical as joints and columns can be subjected to higher force and bond demands during the tests. Table 2 summarises the mechanical characteristics obtained from direct tension tests on each bar size (three samples for each bar). Based on previous research (Helal 2012), commercially available high-strength metal straps with nominal cross section $0.8 \times 25 \mathrm{~mm}$ and zinc corrosion-resistant surface coating were used for 
the PTMS retrofitting. The mechanical properties of the straps were obtained from four sample coupons as reported in Table 2.

Table 2 Mean mechanical properties of steel reinforcement and metal straps

\begin{tabular}{llllll}
\hline Nominal size $(\mathbf{m m})$ & Ø6 & Ø8 & Ø10 & Ø14 & Strap 0.8×25 mm \\
\hline Yield strength, $f_{y}(\mathrm{MPa})$ & $574(6)$ & $544(12)$ & $513(4)$ & $526(8)$ & $982(11)$ \\
Tensile strength, $f_{u}(\mathrm{MPa})$ & $604(9)$ & $572(9)$ & $587(9)$ & $616(2)$ & $1100(22)$ \\
Yield strain, $\varepsilon_{y}(\%)$ & 0.28 & 0.26 & 0.25 & 0.26 & 0.43 \\
Elongation at max. force, $\varepsilon_{u}(\%)$ & $3.0(0.9)$ & $3.3(0.6)$ & $6.8(1.5)$ & $8.0(2.3)$ & $4.60(0.5)$ \\
Elastic modulus, $E_{s}(\%)$ & 207 & 209 & 202 & 201 & 230 \\
\hline
\end{tabular}

Note: standard deviations are shown in parentheses

The bidirectional $\left(0^{\circ}-90^{\circ}\right)$ CFRP sheets used for the retrofitting (see Section 2.5 .2$)$ had $70 \%$ of the fibres oriented in the main longitudinal direction of the sheets. Table 3 summarises the nominal properties of the CFRP sheets, adhesive and full composite data provided by the manufacturer.

Table 3 Mechanical properties of CFRP retrofitting system

\begin{tabular}{|c|c|c|c|c|c|}
\hline & $\begin{array}{l}\text { Tensile } \\
\text { strength } \\
\text { (MPa) }\end{array}$ & $\begin{array}{l}\text { Elastic } \\
\text { modulus } \\
\text { (GPa) }\end{array}$ & $\begin{array}{l}\text { Elongation } \\
\text { at rupture } \\
(\%)\end{array}$ & $\begin{array}{l}\text { Fibre } \\
\text { thickness } \\
(\mathrm{mm})\end{array}$ & $\begin{array}{l}\text { Bond to } \\
\text { concrete } \\
\text { (MPa) }\end{array}$ \\
\hline Torayca T700SC dry fibres & 4900 & 230 & 2.1 & $0.27^{(\mathrm{b})}$ & - \\
\hline Eponal adhesive ${ }^{(\mathrm{a})}$ & $29.3 \pm 1.2$ & $2.3 \pm 0.12$ & $2.4 \pm 0.3$ & - & $>2.5$ \\
\hline Full composite & 1350 & 105 & 1.3 & 0.48 & - \\
\hline
\end{tabular}

(a) Mechanical characteristics in tension after 7 days of hardening at $23^{\circ} \mathrm{C}$

(b) Thickness of $100 \%$ of the CFRP fabric

\subsection{Test setup}

\subsubsection{Building fixity and additional masses}

The building was rigidly fixed to the shake table using stiff steel "shoe" supports clamped with post-tensioned high-strength bolts. The longitudinal column reinforcement was anchored with a $90^{\circ}$ bend welded on the base of the "shoes" to prevent failure at the column-"shoe" interface during the tests at high PGA levels. To simulate additional permanent and variable loads, three steel plates with a total mass of 13.5 tonnes were bolted beneath the $1^{\text {st }}$ floor slab using post-tensioned high-strength bolts, as shown in Fig. 2b. Similarly, one steel plate and 
one concrete block were clamped to the top of the $2^{\text {nd }}$ floor slab to add a mass of 11.0 tonnes. These steel plates were supported on four half-ball steel bearings at the expected slab inflection points to allow free flexural deformation of the slabs during the tests. The estimated selfweight of the building was 20.4 tonnes. The selfweight and the additional masses produced approximate normalised axial load ratios $v=N /\left(f_{c} A_{g}\right)$ of 0.05 and 0.03 for the $1^{\text {st }}$ and $2^{\text {nd }}$ floor columns, respectively, where $N$ is the axial load and $A_{g}$ is the column gross cross sectional area. Such relatively low axial load ratios are common in many substandard low-rise RC buildings with short to medium span lengths between columns (up to $5 \mathrm{~m}$ ).

\subsubsection{Instrumentation}

Fig. 3 shows the location of the horizontal displacement and acceleration transducers used to monitor the response history of each floor during the experiments. To identify possible in-plan torsion, two equidistant displacement transducers were fixed on each exterior face of the slabs. The displacement transducers were attached to a reference external rigid frame to facilitate the measurements and quantify the residual displacements after each test. Relative horizontal displacement between the slabs and the additional masses was also monitored using potentiometers. A series of 59 strategically placed electrical resistance strain gauges monitored the strain developed along the reinforcing steel of selected beams and columns at joints J2A-1X, J2A-2X, J1A-1Y, J1B-1Y and J1A-2Y (see Fig. 2d and e). In testing Phases 4 and 5, 13 additional gauges measured the strain along the metal straps and the main direction of the CFRP sheets. More information about the experimental setup is provided in Mongabure (2012). 


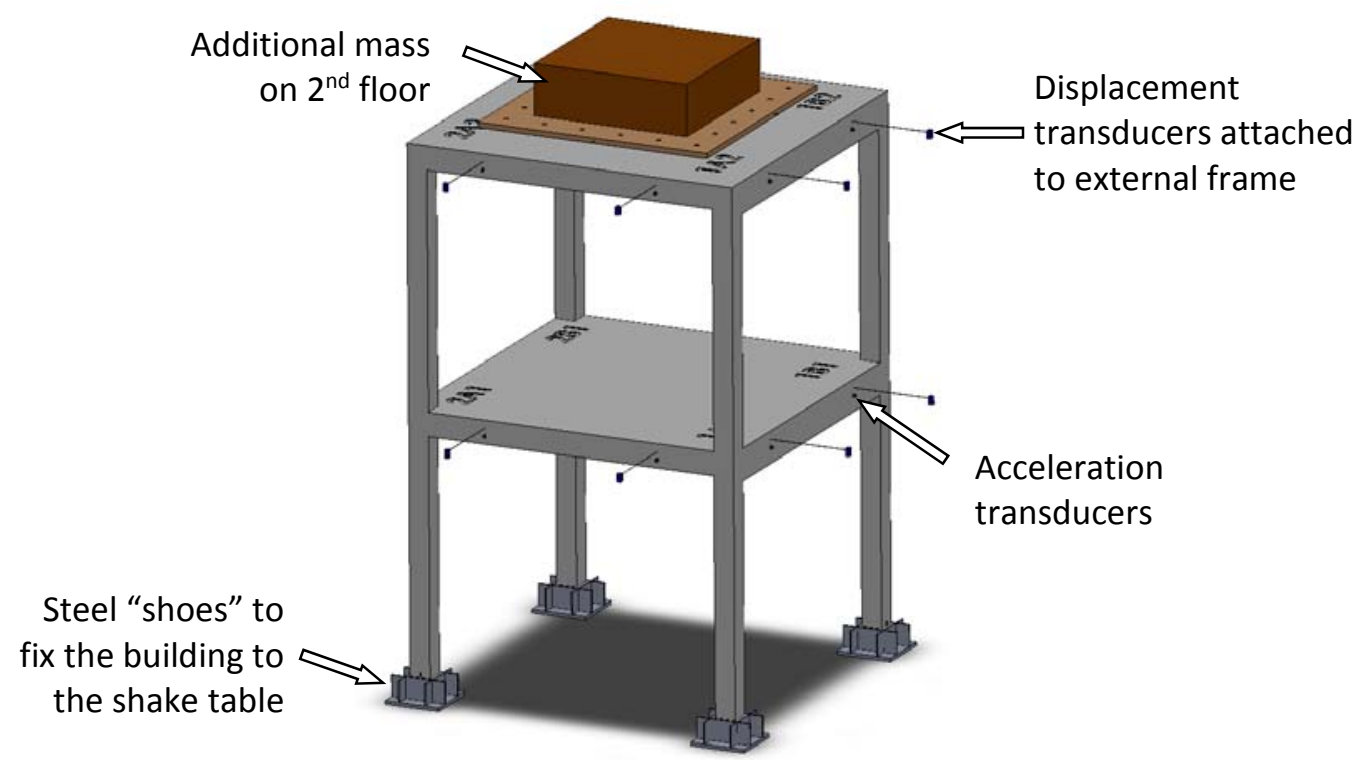

Fig. 3 Displacement and acceleration transducers used to monitor the building response

\subsubsection{Test sequence}

The full testing programme consisted of 30 shaking table tests conducted in five phases according to the sequence summarised in Table 4. Phase 1 of the experiments consisted of shake table excitations in the X direction (i.e. parallel to axes 1 and 2 in Fig. 2a) up to a maximum PGA=0.15g. The main objective of these tests was to investigate the seismic performance of the substandard RC structure and produce significant, but repairable damage. The effectiveness of the PTMS retrofitting technique was then investigated in Phases 2 (X direction) and 3 (Y direction) of the project, but the shaking table tests were halted at a PGA level of $0.35 \mathrm{~g}$ to visually assess damage in the building. To compare the performance of the two retrofitting solutions using CFRP and PTMS, testing Phase 4 subjected the building to input records in the $\mathrm{Y}$ direction, i.e. parallel to frames A and B in Fig. 2a. Finally, the tests in Phase 5 allowed investigating the behaviour of the retrofitted building under severe 3D shaking. 
Table 4 Full test sequence of BANDIT building and dynamic properties after each test, partially adapted from Garcia et al. (2014a)

\begin{tabular}{|c|c|c|c|c|c|c|}
\hline \multirow[b]{2}{*}{ Phase } & \multirow[b]{2}{*}{ Test direction and condition } & \multirow[b]{2}{*}{ PGA (g) } & \multicolumn{2}{|c|}{$\mathrm{X}$ direction } & \multicolumn{2}{|c|}{$Y$ direction } \\
\hline & & & $\begin{array}{l}1^{\text {st }} \text { mode } \\
T_{1}(\mathrm{~s})\end{array}$ & $\begin{array}{l}2^{\text {nd }} \text { mode } \\
T_{2}(\mathrm{~s})\end{array}$ & $\begin{array}{l}1^{\text {st }} \text { mode } \\
T_{1}(\mathrm{~s})\end{array}$ & $\begin{array}{l}2^{\text {nd }} \text { mode } \\
T_{2}(\mathrm{~s})\end{array}$ \\
\hline \multirow[t]{5}{*}{1} & \multirow[t]{5}{*}{$\mathrm{X}$ - Bare building } & Undamaged & $0.48^{(\mathrm{b})}$ & 0.18 & $0.52^{(b)}$ & $\mathrm{NA}$ \\
\hline & & 0.025 & 0.53 & 0.20 & - & - \\
\hline & & 0.05 & 0.60 & 0.22 & - & - \\
\hline & & 0.10 & 0.68 & 0.25 & - & - \\
\hline & & $0.15^{(\mathrm{a})}$ & 0.88 & 0.29 & - & - \\
\hline \multirow[t]{8}{*}{2} & X - Repaired and & Initial & 0.61 & 0.20 & 0.65 & NA \\
\hline & \multirow[t]{7}{*}{ PTMS-retrofitted building } & 0.05 & 0.64 & 0.21 & - & - \\
\hline & & 0.10 & 0.67 & 0.22 & - & - \\
\hline & & 0.15 & 0.68 & 0.23 & - & - \\
\hline & & 0.20 & 0.75 & 0.23 & - & - \\
\hline & & 0.25 & 0.78 & 0.26 & - & - \\
\hline & & 0.30 & 0.88 & 0.26 & - & - \\
\hline & & 0.35 & 1.01 & 0.27 & - & - \\
\hline \multirow[t]{7}{*}{3} & Y - PTMS-retrofitted building & Damaged & - & - & 0.84 & 0.27 \\
\hline & \multirow[t]{6}{*}{$\mathrm{R}_{\mathrm{Y}}$} & 0.05 & - & - & 0.86 & 0.27 \\
\hline & & 0.10 & - & - & 0.93 & 0.27 \\
\hline & & 0.15 & - & - & 0.93 & 0.28 \\
\hline & & 0.20 & - & - & 0.97 & 0.29 \\
\hline & & 0.25 & - & - & 1.08 & 0.29 \\
\hline & & $0.30^{(\mathrm{a})}$ & - & - & 1.11 & 0.30 \\
\hline \multirow[t]{6}{*}{4} & \multirow{2}{*}{$\begin{array}{l}\text { Y - Repaired, CFRP/PTMS- } \\
\text { retrofitted }\end{array}$} & Initial & 0.75 & 0.23 & 0.84 & 0.25 \\
\hline & & 0.05 & - & - & 0.88 & 0.25 \\
\hline & \multirow[t]{4}{*}{$\mathrm{R}_{\mathrm{Y}}$} & 0.10 & - & - & 0.93 & 0.27 \\
\hline & & 0.20 & - & - & 0.99 & 0.28 \\
\hline & & 0.30 & - & - & 1.03 & 0.29 \\
\hline & & 0.35 & - & - & 1.09 & 0.30 \\
\hline \multirow[t]{8}{*}{5} & XY - CFRP/PTMS-retrofitted & 0.10 & 0.95 & 0.27 & 1.09 & 0.30 \\
\hline & XYZ - CFRP/PTMS-retrofitted & 0.10 & 0.99 & 0.28 & 1.20 & 0.31 \\
\hline & \multirow[t]{6}{*}{$\mathrm{R}_{\mathrm{Y}}+0.85 \mathrm{R}_{\mathrm{X}}+0.5 \mathrm{R}_{\mathrm{Z}}$} & 0.20 & 0.97 & 0.29 & 1.20 & 0.31 \\
\hline & & 0.30 & 0.97 & 0.29 & 1.20 & 0.31 \\
\hline & & 0.35 & 1.08 & 0.30 & 1.20 & 0.31 \\
\hline & & 0.40 & 1.06 & 0.31 & 1.20 & 0.32 \\
\hline & & 0.50 & 1.22 & 0.32 & 1.22 & 0.33 \\
\hline & & 0.60 & 1.22 & 0.32 & 1.37 & 0.34 \\
\hline
\end{tabular}

\footnotetext{
(a) After this test, cracks were resin-injected and damaged concrete replaced with high-strength epoxy mortar
}

(b) $T_{i X}=0.48 \mathrm{~s} ; T_{i Y}=0.52 \mathrm{~s}$ 


\subsubsection{Seismic records and dynamic identification}

4 A 30 seconds-long artificial ground motion record based on Eurocode 8 (EC8) soil type C spectra (EN 19985 1:2004, CEN 2004b) was used as horizontal input signal during Phase 4 (see record $R_{Y}$ in Table 4). The ground motion record was scaled to apply different levels of peak ground acceleration (PGA). In Phase 5, two

7 additional records based on EC8 were used as input in the lateral X (record $\mathrm{R}_{\mathrm{X}}$ in Table 4) and vertical (record $8 \mathrm{R}_{\mathrm{Z}}$ ) directions to apply $3 \mathrm{D}$ shaking. However, the PGAs of the input records in the $\mathrm{X}$ and vertical directions 9 were scaled down to $85 \%$ and $50 \%$ of the total in Y direction, respectively (see Table 4). Note that the $85 \%$ scaling is consistent with observations from strong ground motion data (Clough and Penzien 2003) and is

11 suggested for 2D/3D testing by international codes such as the Chinese Seismic Code GB50011-2001 (2001).

12 The vertical record is scaled down by $50 \%$ to consider a ratio of vertical to horizontal (Y) accelerations $\left(a_{v g} / a_{g}\right)$

13 of 0.50 , which is only slightly larger than the value $a_{v g} / a_{g}=0.45$ suggested by EC 8 .

14 In general, a good matching between the input record spectra and the shake table response spectra was observed

15

21 Natural frequencies of the structure were determined before and after each test using a low intensity white noise for the range of frequencies of interest at all excitation levels. For instance, Fig. 4 compares the spectra for the "EC8" for 5\% of critical damping, the "input" record, and the actual response recorded on the "Azalée" shake table at PGA=0.30g. It is shown that the input record spectra matched well the table response spectra of EC8.
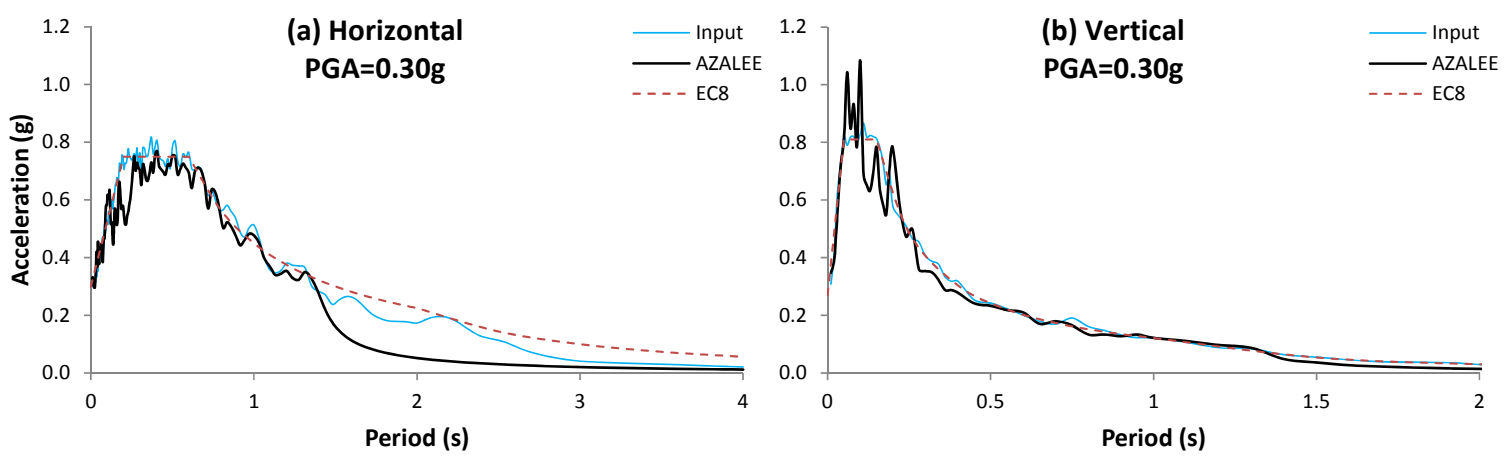

Fig. 4 Matching of input records in (a) horizontal and (b) vertical directions with shake table response and EC8 spectra $(\mathrm{PGA}=0.30 \mathrm{~g})$ excitation (maximum PGA=0.05g) containing a frequency range of $0.5-50 \mathrm{~Hz}$. The response recorded at each floor was then used to identify the natural frequencies of the relevant vibration modes. Accordingly, Table 4 
reports the structural periods of the fundamental $\left(T_{1}\right)$ and second $\left(T_{2}\right)$ vibration modes of the building at the different testing phases. All data were collected by a data acquisition system at a sampling frequency of 600 Hz during 50 seconds.

\subsection{Summary of testing Phases 1 to 3}

The seismic performance of the RC building was initially investigated through a series of unidirectional shake table tests in two orthogonal directions, as reported in Garcia et al. (2014a). Seismic tests were first performed in the $\mathrm{X}$ direction of the bare building (Phase 1). The tests were halted at a PGA=0.15g to avoid a possible collapse of the $2^{\text {nd }}$ floor caused by the premature local failure of the beam-column joints. Such failure was expected due to the short anchorage of the longitudinal beam reinforcement, as shown in Fig. 2e. Subsequently, the damaged concrete at the joints was repaired using high-strength epoxy mortar, the main cracks were epoxyinjected, and the joints and columns were retrofitted using the PTMS technique as shown later in Section 2.5.3. In testing Phases 2 and 3, the PTMS-retrofitted building was subjected to shaking in the $\mathrm{X}$ and $\mathrm{Y}$ directions, respectively. The building sustained medium-intensity earthquakes up to a $\mathrm{PGA}=0.35 \mathrm{~g}$ and maximum interstorey drift ratios $\delta=2.80 \%$ at the $2^{\text {nd }}$ floor. This implies that the structure remained within the Collapse Prevention (CP) performance level according to ASCE/SEI 41-06 (ASCE 2007) (i.e $\delta<4.0 \%$ ) without risking stability. Readings from strain gauges on the longitudinal bars of beam-column joints indicated that the reinforcement remained within the elastic limits during testing Phases 1-3. A visual inspection after testing Phase 3 indicated that the retrofitted building was clearly capable of sustaining seismic excitations at higher PGA levels as the majority of the straps maintained their post-tensioning force. However, the tests were halted to evaluate the local damage at the joints and assess the global condition of the structure.

\subsection{Repairs and seismic retrofitting - Phases 4 and 5}

\subsubsection{Crack injection and concrete patching}

After testing Phase 3, the removal of the metal straps and spalled concrete revealed considerable damage in the $1^{\text {st }}$ and $2^{\text {nd }}$ floor joints, as shown in Fig. 5a-b. Therefore, the damaged joints were repaired for a second time. Firstly, the external top and bottom longitudinal beam bars (with an anchored length of $220 \mathrm{~mm}$ only) were exposed and welded to the column bars to prevent a possible bar pullout in the $2^{\text {nd }}$ floor joints. To achieve this, 
50 some concrete was removed from the joints in the $\mathrm{Y}$ direction and the bars were welded together using single

51 "points" of welding, as shown in Fig. 5c. Although pullout failure of bars was not observed during testing 52 Phases 2 and 3, the welding was carried out to prevent a possible collapse of the $2^{\text {nd }}$ floor during the tests at 53 higher PGA intensities. In real buildings, such welding would be necessary to prevent pullout of the straight 54 longitudinal beam bars if the joints were detailed as shown in Fig. 2e. Damaged and spalled concrete was 55 replaced with high-strength epoxy mortar, and wide cracks were epoxy-injected as shown in Fig. 5d. After the 56 mortar and resin set, the structure was retrofitted with CFRP sheets and PTMS on two opposite frames as 57 described in the following section. 

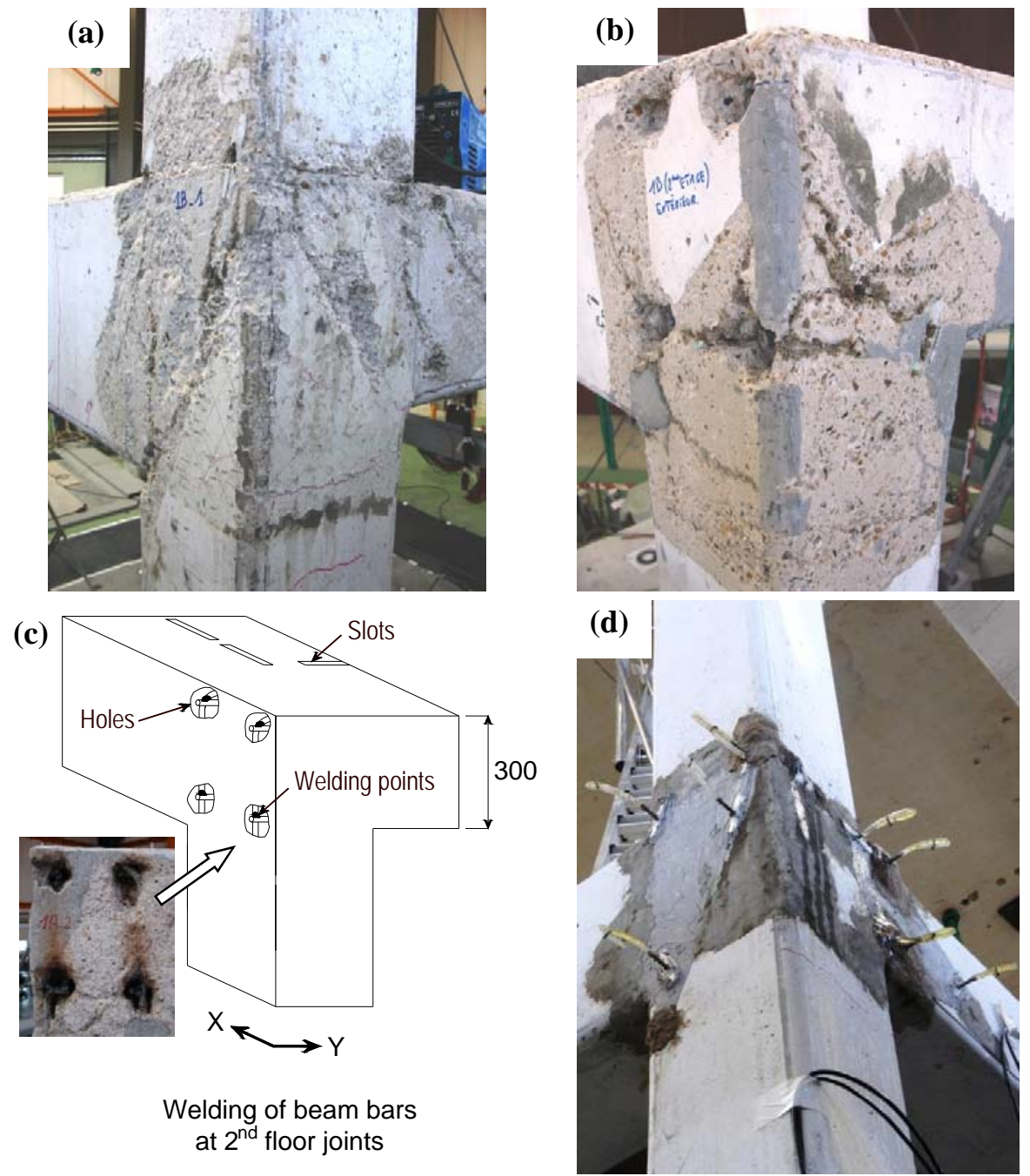

Welding of beam bars at $2^{\text {nd }}$ floor joints

Fig. 5 Observed damage after removal of PTMS in Phase 3 (a) joint J1B-1 and (b) joint J1B-2; (c) welding of longitudinal beam reinforcement to column bars; (d) view of resin injection and concrete patching at joints

\subsubsection{CFRP composites}

63

64

65

66

67

68

69

The dual retrofitting intervention aimed to provide a strong column-weak beam mechanism by preventing the premature failure of the joints and by enhancing the flexural capacity of the columns, thus complying with current seismic design philosophy. Fig. 6 shows a general view of the CFRP retrofitting solution used for frame A of the building. The layout and number of CFRP sheets was similar to that used to retrofit substandard beamcolumn joints and a full-scale building tested previously by the authors (Garcia et al. 2010; Garcia et al. 2014c). Before bonding the CFRP sheets using a wet lay-up procedure, the concrete surfaces were wire brushed and cleaned with pressurised air to enhance adherence. Primer resin was applied at the retrofitting zones to seal the concrete surface. The CFRP sheets were fixed according to the following sequence (see Fig. 6): 


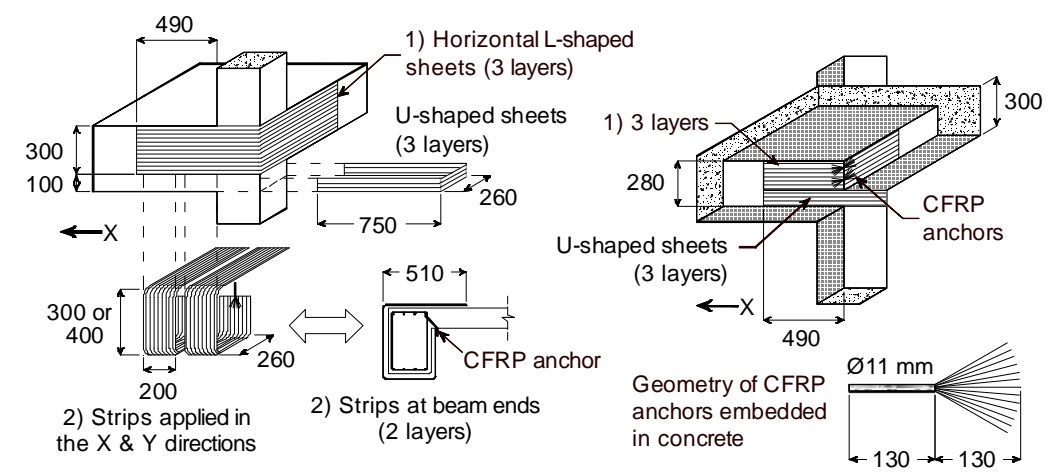

(a) Exterior of joints

(b) Interior of joints

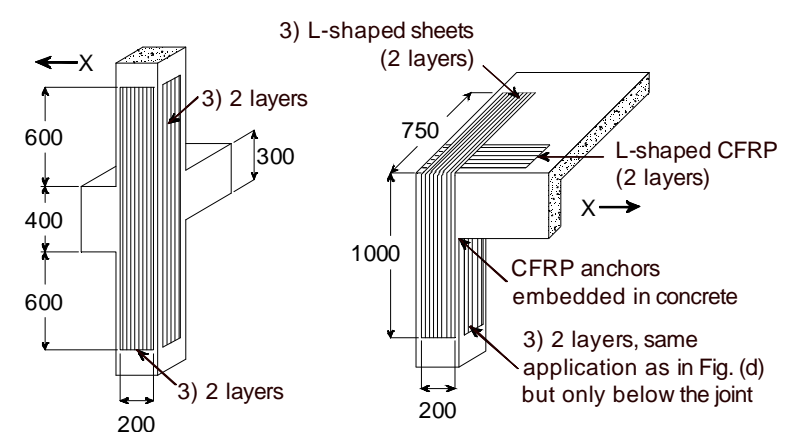

(c) Exterior of columns

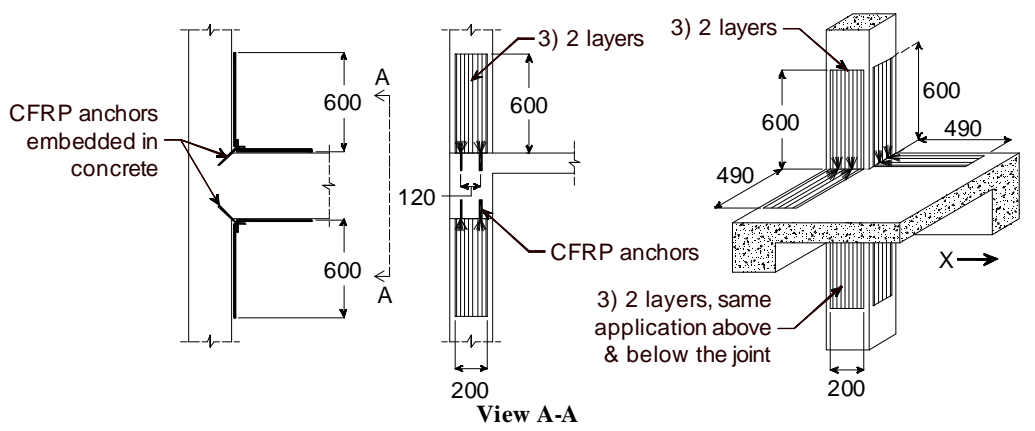

(d) Interior of columns

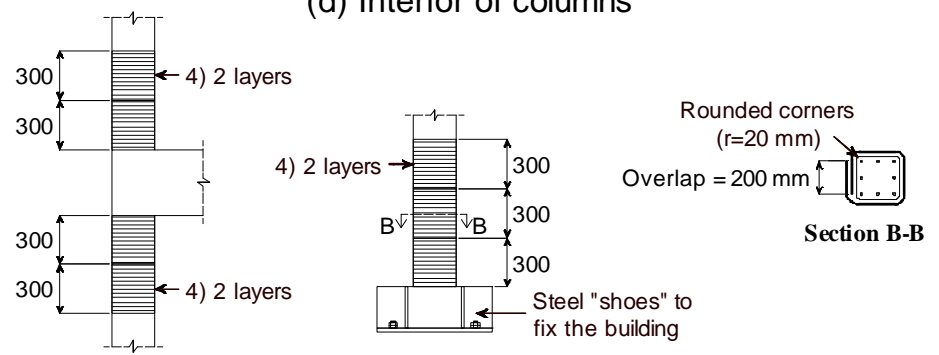

(e) Confinement of columns

72 Fig. 6 Sequence of CFRP retrofitting adopted for frame A (units: mm) 
1) The beam-column joints were first retrofitted using horizontal L-shaped CFRP sheets (3 layers) as shown in

74 Fig. 6a. The three CFRP layers were also bonded to the interior faces of the joints. To prevent premature debonding at the corners, these sheets were anchored mechanically using two CFRP anchors inserted into predrilled holes at the locations shown in Fig. 6b. These anchors were designed to resist the theoretical nominal tensile strength of the fibre sheets.

2) Next, two CFRP strips of $200 \mathrm{~mm}$ width (2 layers) were wrapped around the beams' ends to prevent premature debonding of the horizontal sheets applied to retrofit the joints (see Fig. 6a). One end of the sheets was anchored mechanically to the bottom of the slab using a CFRP anchor.

3) Vertical CFRP sheets (2 layers) were bonded to the exterior (Fig. 6c) and interior (Fig. 6d) faces of the columns' ends to enhance their flexural strength. This resulted in a modest flexural reinforcement ratio $\rho=0.32 \%$ used for the retrofitting. The interior sheets were held using two CFRP anchors (Fig. 6d) to give continuity to the sheets and to avoid drilling slots through the concrete slabs.

4) Finally, the column ends were confined (2 layers) to avoid premature debonding of the longitudinal sheets along the columns axes (Fig. 6e), and to prevent lap splice failures at the bottom of the $2^{\text {nd }}$ floor columns. This led to effective confinement ratios $\alpha \omega_{w}$ of 0.152 and 0.189 for the $1^{\text {st }}$ and $2^{\text {nd }}$ floor columns, respectively, where $\alpha$ is the confinement effectiveness factor and $\omega_{w}$ is the volumetric mechanical ratio defined by EC 8 . As the existing transverse reinforcement was sufficient to prevent shear failure in beams and columns, no additional CFRP reinforcement was provided to prevent this type of failure.

\subsubsection{Post-Tensioned Metal Strapping}

Fig. 7 shows the PTMS retrofitting strategy adopted for frame B. The amount and layout of metal straps is based on the principle that metal straps are treated as conventional tensile reinforcement, and can be designed according to the procedure outlined in Garcia et al. (2014a). The straps were post-tensioned to approximately $30-40 \%$ of their yield strength based on previous experience from tests on columns (Frangou et al. 1995; Moghaddam et al. 2010), and on substandard full-scale joint subassemblies retrofitted with PTMS (Helal 2012). To ensure such post-tensioning force, the tensioning tool was pre-calibrated by applying different levels of air 
Note: a similar anchorage solution is used for the 2 layer straps in columns (parallel to their axes)

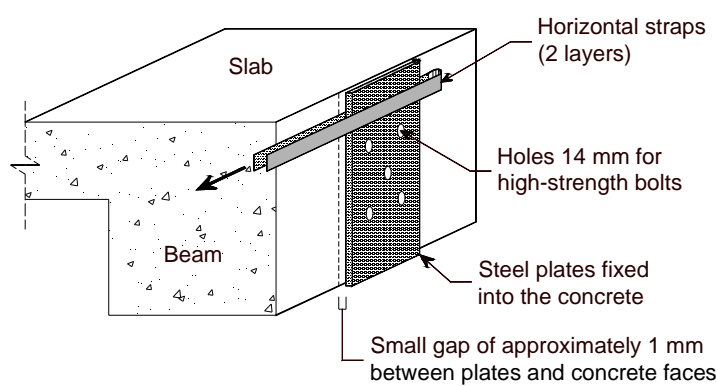

(a) Anchorage for 2 layer straps

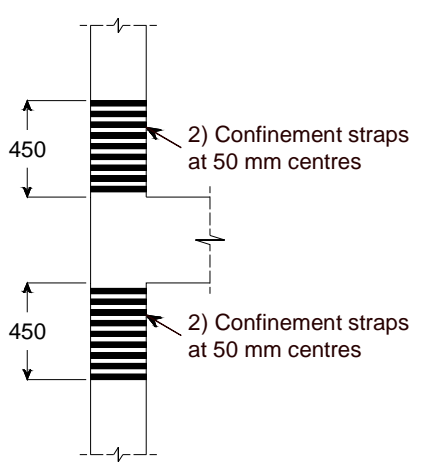

(b) PTMS confinement at columns ends

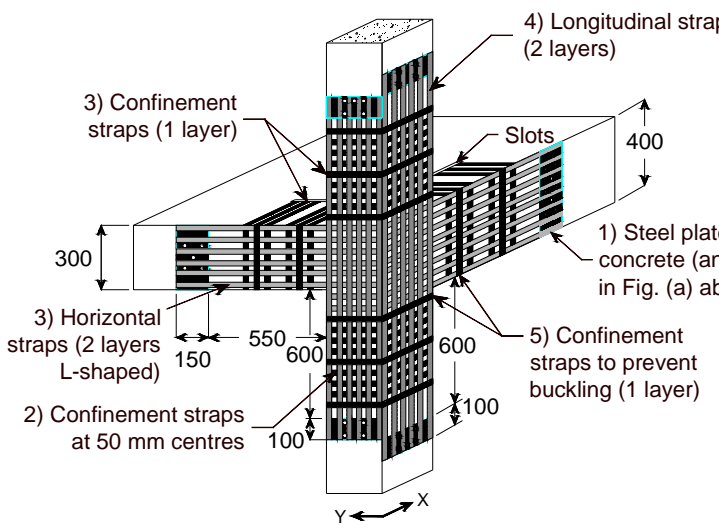

(d) $1^{\text {st }}$ floor joint

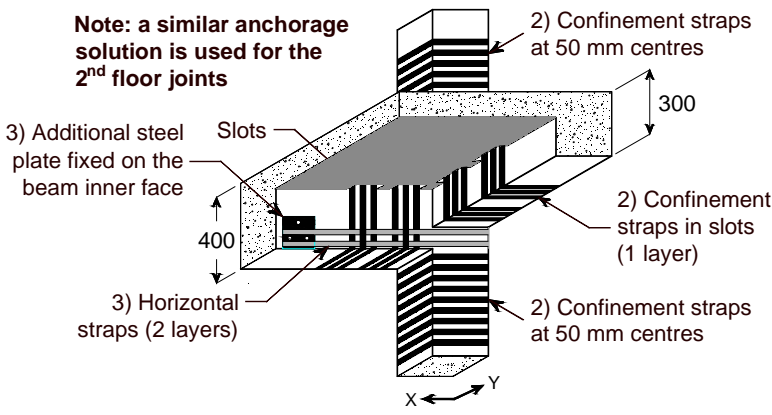

(c) $1^{\text {st }}$ floor joint (interior view)

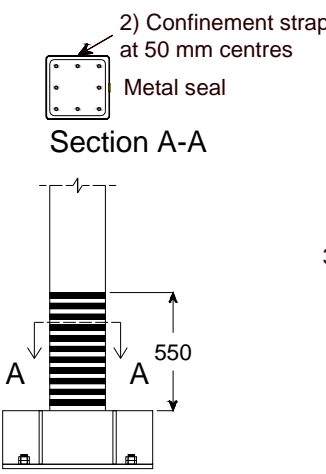


plates were positioned and partially tightened with nuts and washers leaving a small gap of approximately 1

$106 \mathrm{~mm}$ between the plates and the concrete faces, which was necessary to secure the 2 layer of metal straps (see

107 Fig. 7a). For practical purposes, the steel plates were staggered to prevent congestion of the steel bolts at a

108 single beam or column section. The sharp corners of the anchoring plates in contact with the metal straps were

109 rounded off to a ratio of $5 \mathrm{~mm}$ to reduce stress concentrations and possible strap rupture. The diameter of the

110 high-strength bolts and dimensions of the steel plates were designed to resist the shear force corresponding to

111 the nominal tensile strength of the metal straps.

112 2) Next, horizontal straps at $50 \mathrm{~mm}$ spacing were placed at the columns ends (see Fig. $7 \mathrm{~b}$ ) to provide 113 confinement and increase their shear strength, thus resulting in $\alpha \omega_{w}=0.054$ and 0.067 the $1^{\text {st }}$ floor and $2^{\text {nd }}$ floor 114 columns, respectively (i.e. approximately $1 / 3$ of the confinement applied on the CFRP-retrofitted frame).

115 Additionally, one layer of straps was inserted in the pre-formed slots of the slabs to confine the beams ends and 116 also increase their shear capacity (Fig. 7c).

117 3) Eight straps (2 layers each) were installed parallel to the longitudinal beams axes (i.e. horizontally) at 50

$118 \mathrm{~mm}$ centres to provide confinement to the beam-column joint. These straps were anchored around the steel 119 plates as shown in Fig. 7d-e. Due to the different beam depths in the X and Y directions, two of these straps 120 were anchored using an additional anchorage plate at the interior face of the deeper beams, as shown in Fig. $121 \quad 7 \mathrm{c}$.

122 4) Six straps (2 layers each) were provided along the exterior faces of the columns to enhance their flexural 123 capacity, which lead to a retrofitting flexural reinforcement ratio $\rho=0.38 \%$ parallel to the columns' axis. For 124 the $2^{\text {nd }}$ floor joints, the six straps were bent at $90^{\circ}$ at the slab edges and secured to steel plates located on the 125 top of the $2^{\text {nd }}$ floor slab. Subsequently, the nuts of the bolts securing the steel plates were tightened by hand 126 using a spanner to prevent the loss of tension force in the straps (Fig. 7d-e). The longitudinal column straps 127 were curtailed at a distance of $600 \mathrm{~mm}$ from the beams (see Fig. 7d-e), where the column flexural strength was 128 sufficient to resist the seismic demand. 
129 5) Finally, 1 layer of confinement straps was placed around beams and columns to prevent excessive buckling

130 of the horizontal and longitudinal straps installed during steps 3 and 4 (Fig. 7d-e).

131 All straps were fastened using mild-steel push type seals of $25 \mathrm{~mm}$ length. Such seals are typically used in the 132 packaging industry due to their low cost and ease of installation using common strapping tools. As shown in 133 Fig. 8, the tensioning force was maintained mechanically with notches produced using the clamping jaws (four 134 notches per metal seal). As shown in the video (Online Resource 1), the installation of the metal straps was 135 performed swiftly without the need of using heavy equipment or sophisticated safety gear.

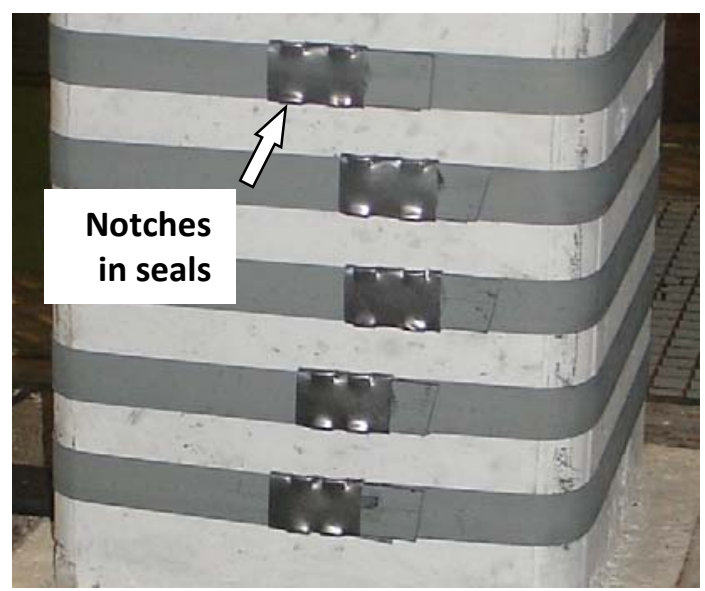

137 Fig. 8 Close up view of metal seals after fastening

138 Table 5 summarises the flexural strength of beams and columns of the bare and retrofitted building for the $\mathrm{X}$ 139 direction. It is shown that the PTMS and CFRP retrofitting solutions increased the flexural strength of beams 140 and columns by minimum 30\% to comply with the strength hierarchy in code-compliant joints imposed by EC 8 141 (i.e. $\Sigma M_{\text {Rcol }}>1.3 \Sigma M_{\text {Rbeam }}$ ). It should be noted that the values in Table 5 were calculated using conventional 142 moment-curvature analysis assuming 1) no post-tensioning losses in the metal straps, 2) perfect bond between 143 CFRP sheets and concrete, and 3) that the straight beam reinforcement did not pullout from the joint, as 144 confirmed during the tests in the retrofitted condition (see next section). 
Table 5 Beam and column flexural strengths of BANDIT building

\begin{tabular}{|c|c|c|c|c|c|c|}
\hline & \multicolumn{2}{|c|}{ Bare condition } & \multicolumn{2}{|c|}{ PTMS-retrofitted } & \multicolumn{2}{|c|}{ CFRP-retrofitted } \\
\hline & $M_{y}$ & $M_{u}$ & $M_{y}$ & $M_{u}^{(b)}$ & $M_{y}$ & $M_{u}{ }^{(b)}$ \\
\hline Column $2^{\text {nd }}$ floor & 38 & 41 & 92 & 102 & 51 & 83 \\
\hline Column $1^{\text {st }}$ floor & 63 & 77 & 101 & 119 & 77 & 105 \\
\hline Beams $\mathrm{X}$ direction (positive) & 79 & 88 & 149 & 172 & 93 & 182 \\
\hline $\begin{array}{l}\text { Beams X direction } \\
\text { (negative) }^{(a)}\end{array}$ & 108 & 113 & 188 & 208 & 123 & 169 \\
\hline
\end{tabular}

(a) The effective tension flange was computed according to Eurocode 2 (CEN 2004a)

(b) Values at concrete crushing

Fig. 9 shows the building after the retrofitting intervention. As shown in Fig. 9a, the metal strapping provided completely the beam-column connection (Fig. 9c).

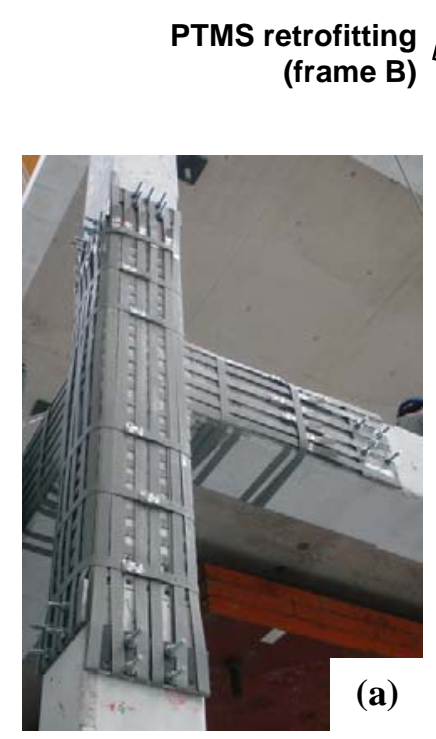

(b)

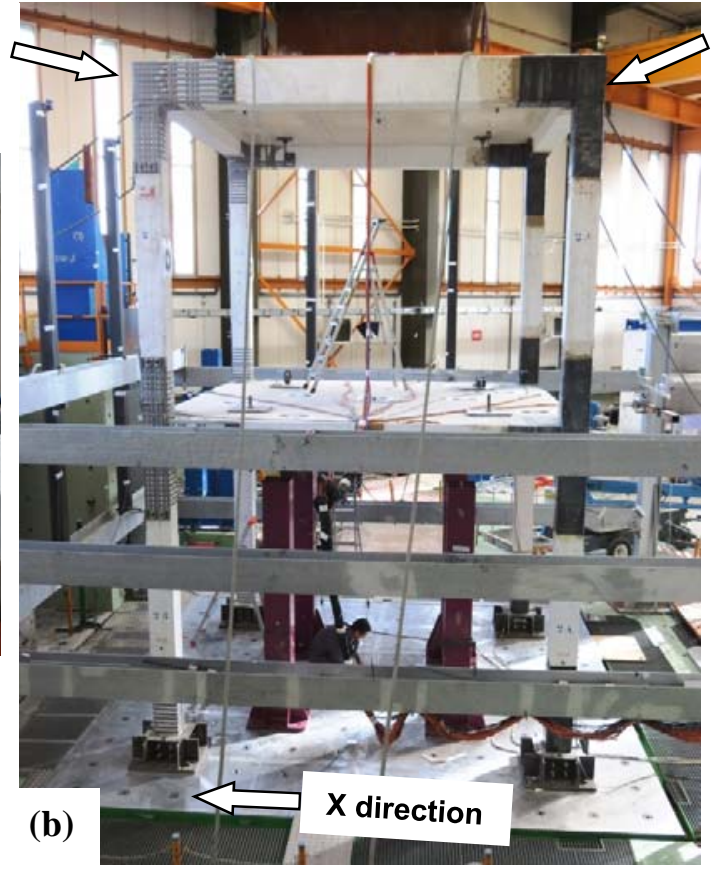

CFRP retrofitting (frame A)

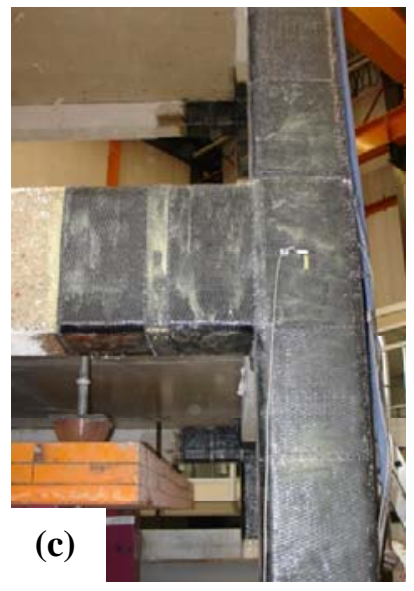

Fig. 9 View of the building after the CFRP/PTMS retrofitting: (a) PTMS-retrofitted joint; (b) general view on shaking table, and (c) CFRP-retrofitted joint

\section{Test results and discussion}

\subsection{Phase 4: tests in Y direction}

The seismic excitation applied to the building after the repairs and dual CFRP/PTMS retrofitting ranged from PGA $0.05 \mathrm{~g}$ to $0.35 \mathrm{~g}$ (see Table 4). In general, as the CFRP sheets and metal straps covered the concrete 
surfaces, damage at the joints could not be observed during the tests. However, popping and metallic sounds during tests (especially after the test at $\mathrm{PGA}=0.20 \mathrm{~g}$ ) indicated that the CFRP and metal straps were effectively carrying considerable tension forces. After the tests were halted, a visual inspection revealed that no apparent

159 damage was caused on the straps or on the CFRP sheets. Overall, the metal straps maintained most of the post-

160 tensioning force, with the exception of some longitudinal straps placed along the columns of the $1^{\text {st }}$ floor joints.

161 This loss of force can be attributed to the partial shearing off of some push type metal seals, which had poor bearing resistance to start with. Some cracking was also evident at the beam-column joints, but only on frame

163 B where the PTMS retrofitting was applied. The damage observed in the building in Phase 4 indicated that the repairs and CFRP/PTMS retrofitting intervention prevented the premature shear failure of the deficient joints.

165 As the tested building is low-rise, symmetric and regular in plan and elevation, the first mode is expected to 166 dominate the structural response (e.g. Thermou and Pantazopoulou (2011)). Therefore, this study adopts an 167 equivalent SDOF model to calculate the global lateral stiffness of the structure $(K)$ during testing Phase 4 . Fig. 16810 shows that the repairs and retrofitting restored the stiffness of the building from $K=1430 \mathrm{kN} / \mathrm{m}$ (end of Phase 169 3) to $2510 \mathrm{kN} / \mathrm{m}$ (beginning of Phase 4), i.e. an enhancement of $75 \%$. At the end of Phase 4 (PGA=0.35g), 170 damage accumulation degraded the stiffness of the original bare building by $77 \%$ (from $6600 \mathrm{kN} / \mathrm{m}$ at the 171 beginning of Phase 1 to $1500 \mathrm{kN} / \mathrm{m}$ ). Despite this severe stiffness reduction, the limited structural damage 172 observed after Phase 4 indicated that the building was capable of sustaining seismic shaking at higher 173 intensities.

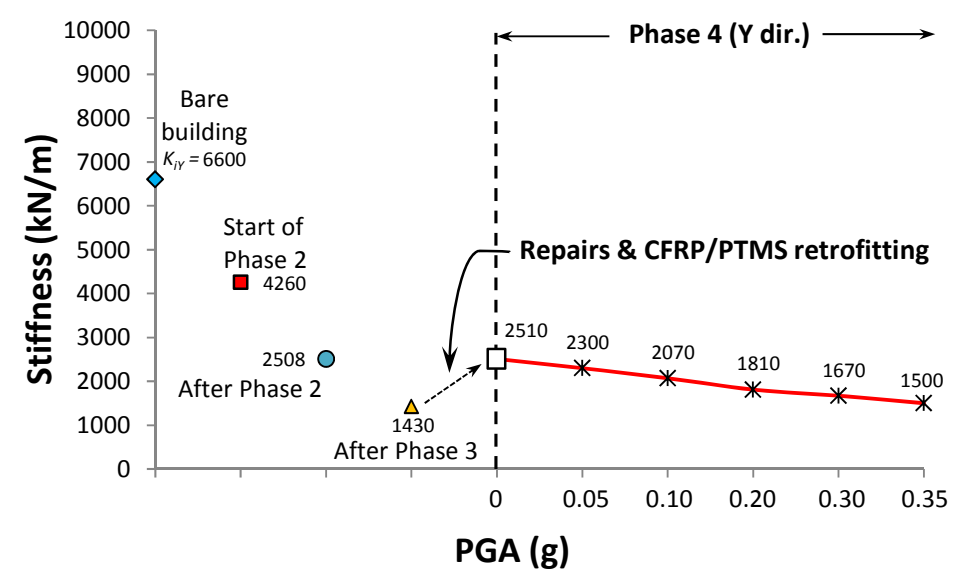




\subsection{Phase 5: 3D tests}

The seismic excitation applied to the building ranged from PGA $0.10 \mathrm{~g}$ to $0.60 \mathrm{~g}$ (Table 4). As for Phase 4, damage at the joints could not be observed during the tests. However, popping and metallic sounds after the test at $\mathrm{PGA}=0.35 \mathrm{~g}$ indicated that the CFRP sheets and metal straps were carrying considerable tension forces. At PGA $=0.40 \mathrm{~g}$, several of the push type metal seals sheared off (especially at the joints), thus leading to partial loss of the post-tensioning force in the straps.

During the last tests at $\mathrm{PGA}=0.50 \mathrm{~g}$ and $0.60 \mathrm{~g}$, some of the high-strength bolts used to fix the steel plates into the $2^{\text {nd }}$ floor columns bent due to the excessive shearing force applied by the metal straps. This was accompanied by the opening of a gap between some of the anchoring plates and the column faces (similar to that shown in Fig. 7a), leading to further loss of tension force in the straps. A visual inspection after the tests revealed some horizontal cracking and concrete crushing at the base of the $2^{\text {nd }}$ floor columns of frame B (see Fig. 11a). Moreover, some of the concrete cover spalled off in the Y direction of column C1B-2Y (Fig. 11b) probably due to the high pulling force applied by the plate and bolts. Whilst some metal seals and high-strength bolts experienced minor local damage during this test Phase, frame B maintained its stability at high seismic excitation levels. Based on these experimental observations, it is evident that the anchoring system was effective to prevent failure of the strapping intervention. Nonetheless, further research is necessary to investigate the effectiveness of the anchoring system on low-strength concrete, where the anchoring bolts may cause damage to the surrounding concrete.

\section{(a)}

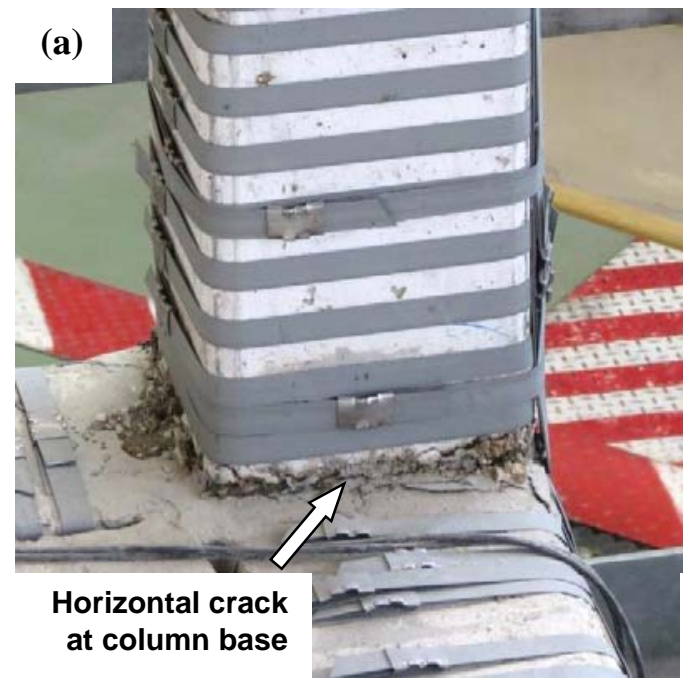

(b)

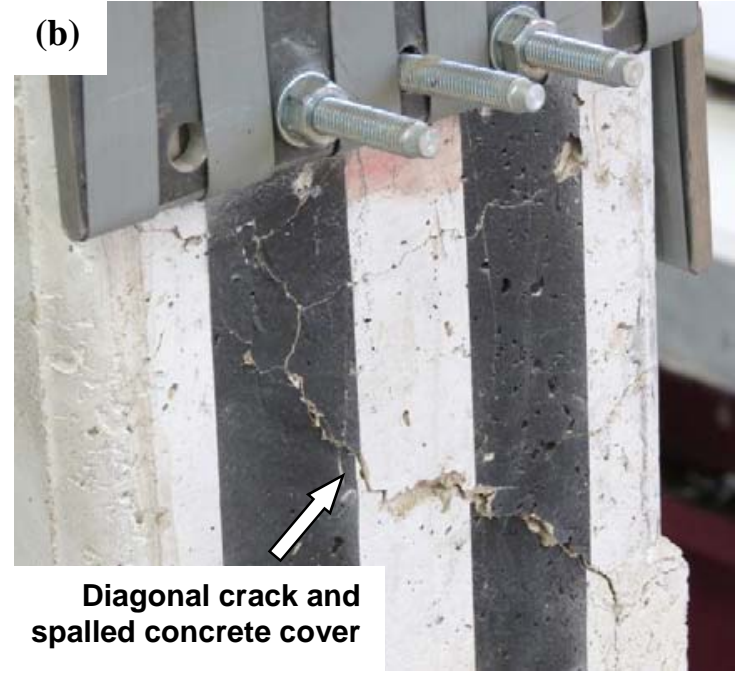


195 Fig. 11 (a) Typical horizontal crack at the base of the $2^{\text {nd }}$ floor columns of frame B; (b) diagonal crack and spalled concrete 196 cover in column C1B-2Y (Y direction)

197 A post-test visual inspection and video recordings (Online Resource 2) also indicated that horizontal cracks as

198 that shown in Fig. 11a also formed at the base of the $2^{\text {nd }}$ floor columns of frame A. This was confirmed by

199 minor local debonding of some vertical CFRP sheets (see Fig. 12a) during the final seismic test at PGA=0.60g.

200 However, the crack opening was controlled by the CFRP anchors embedded at the inner faces of the columns

201 (see Fig. 6b). Minor debonding and CFRP fracture was also observed at some locations of the beam-column 202 joints (Fig. 12b-c). 


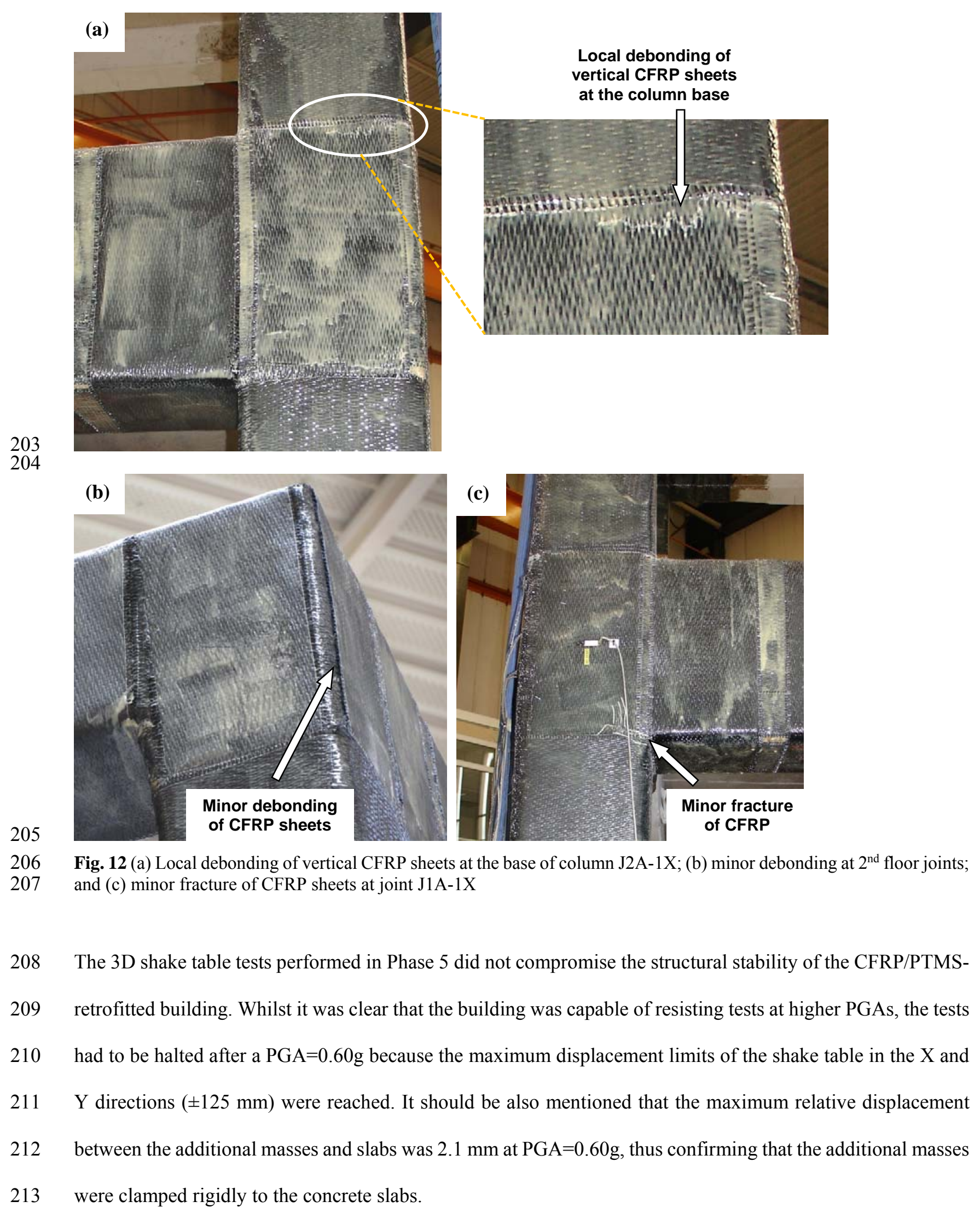


214 Fig. 13a-b show the lateral stiffness degradation in the $\mathrm{X}$ and $\mathrm{Y}$ directions, respectively. Compared to the 215 stiffness observed in the $\mathrm{Y}$ direction after Phase $4(1500 \mathrm{kN} / \mathrm{m})$, the stiffness after the first test of Phase 5 216 degraded by $19 \%(1220 \mathrm{kN} / \mathrm{m})$. The results also indicate that the lateral stiffness in the $\mathrm{X}$ direction deteriorated 217 at a faster rate (from 1950 after Phase 4 to $1190 \mathrm{kN} / \mathrm{m}$ ) in comparison to the $\mathrm{Y}$ direction. This can be attributed 218 to the damage produced in the $\mathrm{Y}$ direction in Phase 4. At the end of the test programme, the residual stiffness 219 of the building in both the $\mathrm{X}$ and $\mathrm{Y}$ directions was only $15 \%$ of the original stiffness (see $K_{i X}$ and $K_{i Y}$ values in Fig. 13a-b).
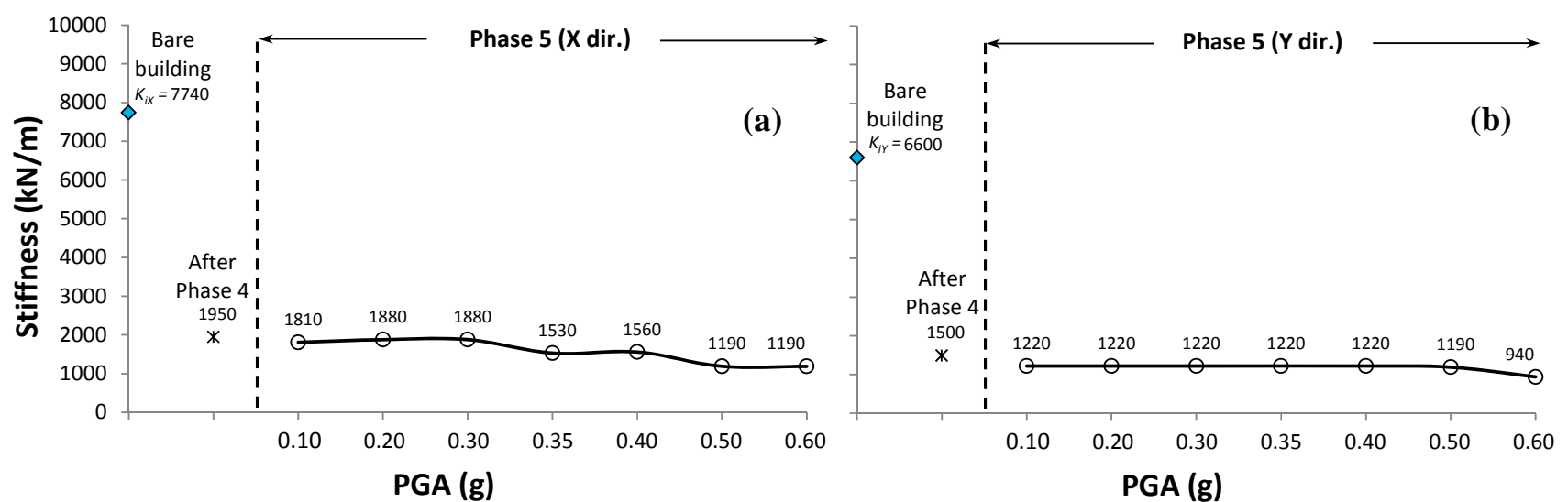

222 Fig. 13 Evolution of lateral stiffness during testing Phase 5 in the (a) $\mathrm{X}$ and (b) $\mathrm{Y}$ directions

\subsection{Global damage index}

Research has suggested that the progression of global damage in buildings subjected to earthquakes can be evaluated using the shift in fundamental structural period (DiPasquale et al. 1990; Zembaty et al. 2006; Kyriakides et al. 2014). Therefore, this study adopts the global damage index (DI) developed by DiPasquale et al. (1990) to assess quantitatively the progress of structural damage at different PGA intensities, as defined by Equation (1):

$$
D I=1-\left(\frac{T_{i}}{T_{f}}\right)^{2}
$$

229 where $T_{i}$ and $T_{f}$ are the natural periods of the building in initial (undamaged) condition and after an earthquake, 230 respectively. Accordingly, $D I=0$ implies no damage to the building, whereas $D I \approx 1.0$ represents theoretical 231 building 'collapse'. Fig. 14 shows the global DIs calculated for each shake table test using Equation (1). For 
each direction of testing, $T_{i}$ was taken as the initial period of the bare undamaged building in that direction ( $T_{i X}=0.48 \mathrm{~s}$ and $T_{i Y}=0.52 \mathrm{~s}$ ), whereas $T_{f}$ was taken as the period after each shake table test as summarised in Table 4. It should be noted that any global damage index has to be calibrated with test and field data before it can be directly associated to a specific damage state or performance limit. Therefore, the DI proposed by DiPasquale et al. (1990) is used in this study only to compare quantitatively the progression of global structural damage experienced by the building during testing Phases 1, 4 and 5 .

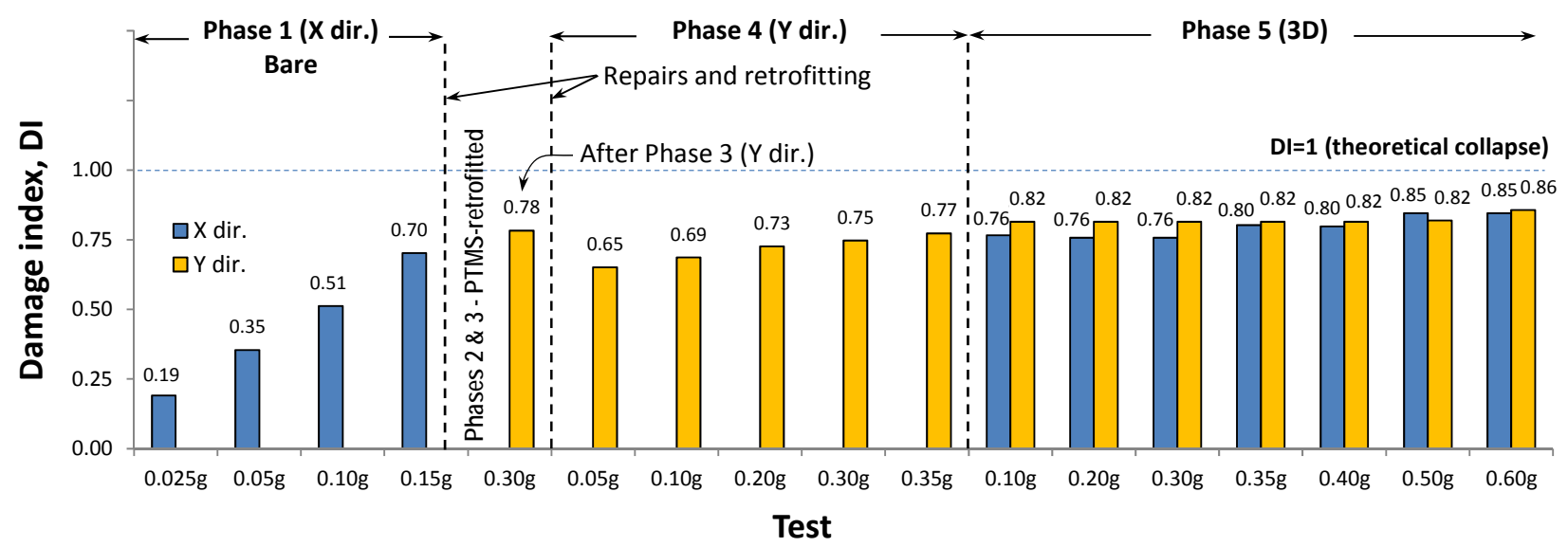

Fig. 14 Global damage index (Phases 1, 4 and 5), partially adapted from Garcia et al. (2014a)

Fig. 14 indicates that at a PGA $=0.05 \mathrm{~g}$, the $D I$ of the CFRP/PTMS-retrofitted building was 0.65 , which implies that the applied repairs and retrofitting reduced damage by $17 \%$ with reference to the last test of Phase 3 ( $D I=0.78$ in the $\mathrm{Y}$ direction). Overall, the evolution of damage during Phase 4 was gradual, which agrees well with the experimental observations. At the end of Phase 4 at $\mathrm{PGA}=0.35 \mathrm{~g}$, the global damage $(D I=0.77)$ was similar to that observed at the end of Phase 3 but at a lower PGA $=0.30 \mathrm{~g}(D I=0.78)$. This implies that the seismic performance of the dual retrofitted structure (i.e. Phase 4) improved compared to the structure with only PTMS retrofitting. It should be mentioned that, in addition to the CFRP/PTMS-retrofitting, the welding of the longitudinal beam and column bars may have also contributed to enhance the seismic performance of the retrofitted building. However, the similar strain gauge readings recorded during Phase 3 (before welding) and Phase 4 (after welding) at the same PGA=0.30g (Fig. 15) indicate that the welding contribution was negligible when the beam bars were tensioned. Nonetheless, the repairs and the welding have contributed to reducing 
251 strain in compression after $27 \mathrm{~s}$ of shaking when joint damage occurred in Phase 3 , as indicated by a sharp 252 increase in compressive strain at that time.

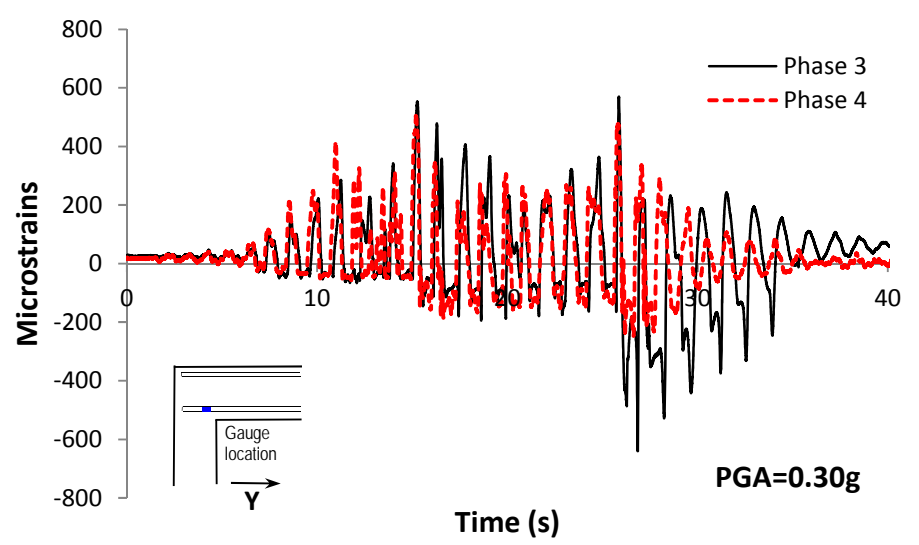

Fig. 15 Comparison of strain gauge readings recorded during Phase 3 (before welding) and Phase 4 (after welding) at $\mathrm{PGA}=0.30 \mathrm{~g}$ (frame A)

Compared to Phase 4, the $D I$ in the Y direction during Phase 5 increased slightly to 0.82 after the first 3D seismic test at $\mathrm{PGA}=0.10 \mathrm{~g}$. Fig. 14 shows that damage in the $\mathrm{Y}$ direction remained constant $(D I=0.82)$ up to a PGA $=0.50 \mathrm{~g}$, thus indicating most of the damage in this direction was produced during Phase 4 . The $D I$ in the

259 X direction was 0.76 at the start of Phase 5, which is only 9\% higher than that observed at the end of Phase 1 $260(D I=0.70)$, where the tests were halted due to considerable local damage in the joints. Damage in the X direction 261 increased progressively with the level of PGA up to $D I=0.85$ at PGA $=0.60 \mathrm{~g}$. Despite the considerable damage accumulated at the end of the 3D tests, none of the frames strengthened with either CFRP sheets or PTMS were 263 near collapse.

264 The global damage index results indicate that damage was well controlled in the PTMS/CFRP-retrofitted 265 building even at high levels of PGA 3D shaking. This confirms that both retrofitting techniques were very 266 effective at maintaining structural stability, thus preventing the potential collapse of the building.

\subsection{Performance levels}

268 Current guidelines for seismic assessment and retrofit of existing buildings such as ASCE/SEI 41-06 (ASCE 2007) establish limits on acceptable values of maximum interstorey drift ratios, implying that exceeding these 
270 limits is a violation of a performance objective. According to ASCE/SEI 41-06, maximum transient drift ratios 271 of $\delta=1.0 \%, 2.0 \%$ and $4.0 \%$ correspond to Immediate Occupancy (IO), Life Safety (LS), and Collapse 272 Prevention (CP) performance levels, respectively.

273 Fig. 16a compares the maximum interstorey drift ratios of the $1^{\text {st }}$ and $2^{\text {nd }}$ floor of the CFRP and PTMS274 retrofitted frames. The figure includes the results from the two equidistant displacement transducers fixed on 275 each exterior face of the slabs, labelled as "CFRP" and "PTMS" according to the retrofitting technique used on 276 each frame. It is shown that the $1^{\text {st }}$ and $2^{\text {nd }}$ floors of the retrofitted building had similar $\delta$ s at all PGA levels. 277 This implies that the both CFRP/PTMS retrofitting solutions led to a more uniform damage distribution over 278 the building height, which allowed a better exploitation of the available members' capacity (Hajirasouliha et 279 al. 2012). The building remained safely within the CP performance level during the last test at PGA=0.35g $280(\delta=2.92 \%)$. Overall, maximum drift values of the "PTMS" frame were only $2-6 \%$ larger than those of the 281 "CFRP" frame, thus indicating that some negligible in-plan torsion occurred during the 3D tests. 
(a)

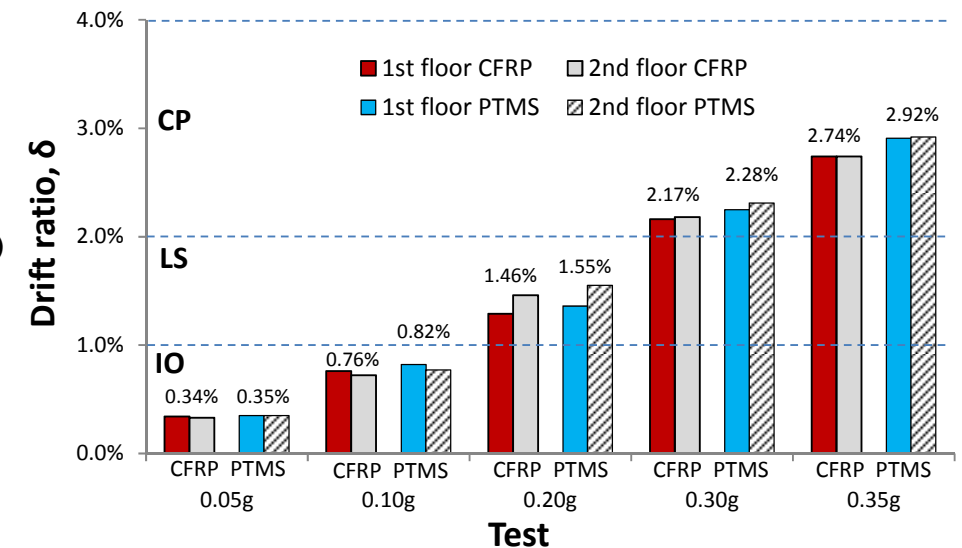

(b)

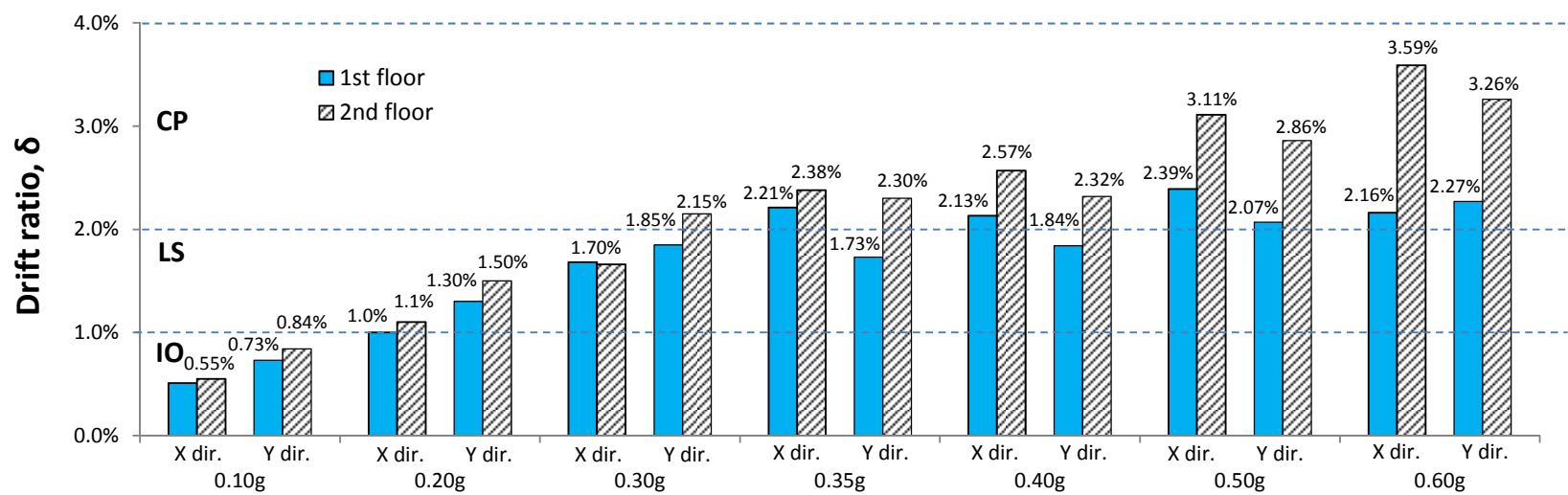

285 Fig. 16 Interstorey drift ratio of $1^{\text {st }}$ and $2^{\text {nd }}$ floors during (a) Phase 4 (Y dir.), and (b) Phase 5 (3D)

Fig. 16b compares maximum interstorey drift ratios for the $\mathrm{X}$ and $\mathrm{Y}$ directions of the PTMS-retrofitted frame (i.e. the most critical) during Phase 5. At PGA levels between 0.10 and $0.30 \mathrm{~g}$, drifts in the $\mathrm{Y}$ direction were 10$40 \%$ larger than those in the $\mathrm{X}$ direction. Conversely, slightly larger drifts were observed in the $\mathrm{X}$ direction after a PGA $=0.35 \mathrm{~g}$. Whilst the drift values measured at the $2^{\text {nd }}$ floor $(\delta=3.59 \%)$ were close to the theoretical

$290 \mathrm{CP}$ limit $(\delta=4.0 \%)$ at a PGA $=0.60 \mathrm{~g}$, the building did not show evidence of structural failure. In comparison to 291 the original bare building (Phase 1), the CFRP/PTMS retrofitting intervention enhanced the maximum drift 292 capacity from $0.82 \%$ to $2.16 \%$ for the $1^{\text {st }}$ floor $(+160 \%)$, and from $1.69 \%$ to $3.59 \%$ for the $2^{\text {nd }}$ floor $(+110 \%)$.

293 This enhancement in lateral deformation improved considerably the behaviour of the $2^{\text {nd }}$ floor, which was near collapse at a much lower PGA=0.15g during Phase 1 . 
Whilst the building was tested up to a drift level close to the theoretical collapse, the experimental observations indicated that its residual capacity was not yet exhausted. Nonetheless, as it was mentioned before, the tests had to be halted after the test at $\mathrm{PGA}=0.60 \mathrm{~g}$ because the maximum displacement limits of the shake table were reached.

\subsection{Local strains}

To assess the effective force taken by the retrofitting solutions, local strains were monitored using foil-type strain gauges fixed on the CFRP sheets and metal straps. Fig. 17 shows the location of two equivalent strain gauges (placed on opposite frames A and B) and their corresponding development of strains during the last test at PGA $=0.60 \mathrm{~g}$ (Phase 5). These are typical results and the following observations apply to all gauges. As shown in Fig. 17, elastic strains of up to 5000 and $1300 \mu \varepsilon$ were recorded in the CFRP sheets and metal straps, respectively. In all cases, maximum CFRP strains remained below the rupture strain of the sheets, whereas no yielding occurred in the metal straps. Readings from strain gauges fixed on the longitudinal beam bars of the $1^{\text {st }}$ floor joints showed that the onset of yielding occurred during Phase 4 at a PGA $=0.30 \mathrm{~g}$ (see Fig. 18), thus confirming that a strong column-weak beam behaviour was achieved in line with current seismic design philosophy. However, yielding was limited as the CFRP/PTMS retrofitting also sustained the tensile forces acting on the beams and columns, as evidenced by the local debonding of the CFRP sheets and shearing off of some metal clips.

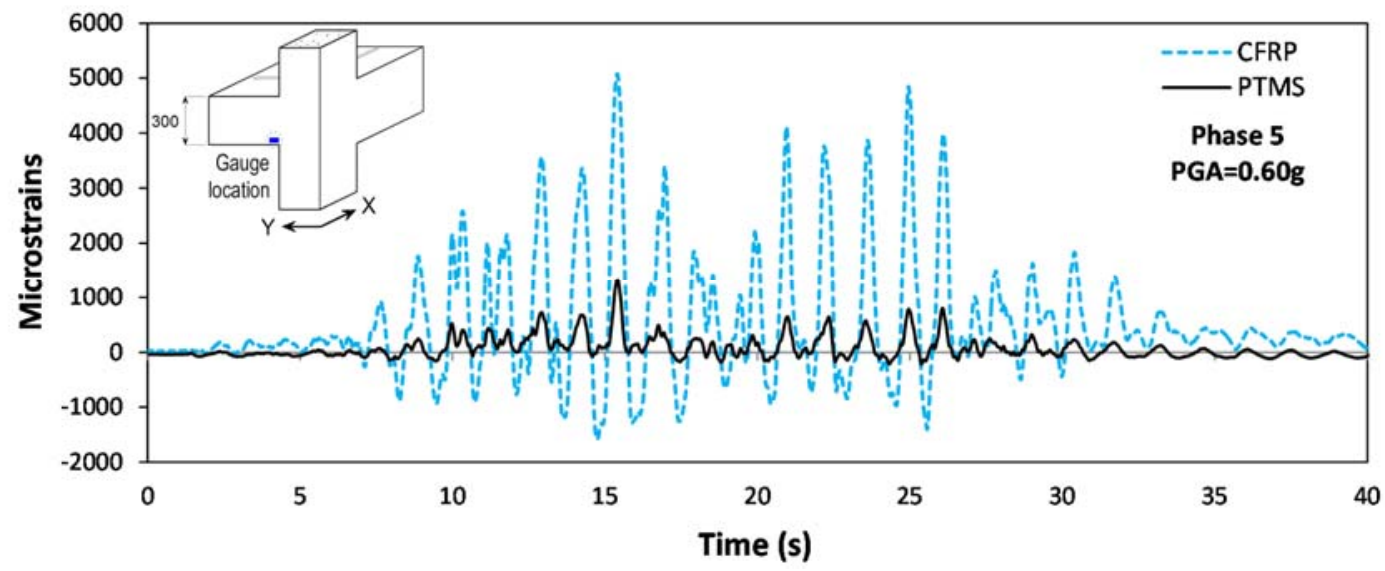

Fig. 17 Strain time-history of CFRP sheets and metal straps during $3 \mathrm{D}$ test at $\mathrm{PGA}=0.60 \mathrm{~g}$ 


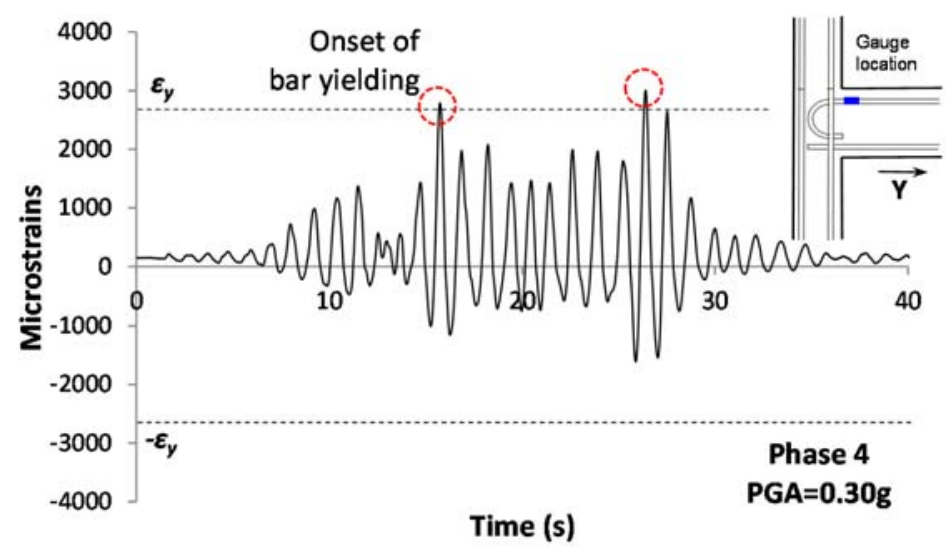

Fig. 18 Strains time-history of longitudinal beam reinforcement in test at PGA $=0.30 \mathrm{~g}$ (Phase 4)

Fig. 19 compares accumulated residual strains from four critical gauges fixed on beams and columns of the CFRP and PTMS frames of the retrofitted building (Phases 4 and 5). For instance, CFRP-B and CFRP-C correspond to gauges located at the beam and column of frame A, respectively. It is shown that, as a result of accumulated damage in the building, the strains in the CFRP sheets increased progressively with the applied PGA up to $1300 \mu \varepsilon$ (PGA=0.60g in Phase 5). Conversely, the residual PTMS strains reduced gradually (up to 400-500 $\mu \varepsilon$ at the end of Phase 5) due to some local damage of the push type seals, which led to stress relaxation in the straps. Despite this loss of some tensioning force, it is estimated that the straps maintained $70-80 \%$ of their initial force, thus confirming the reliability of the PTMS technique at high seismic excitation levels.

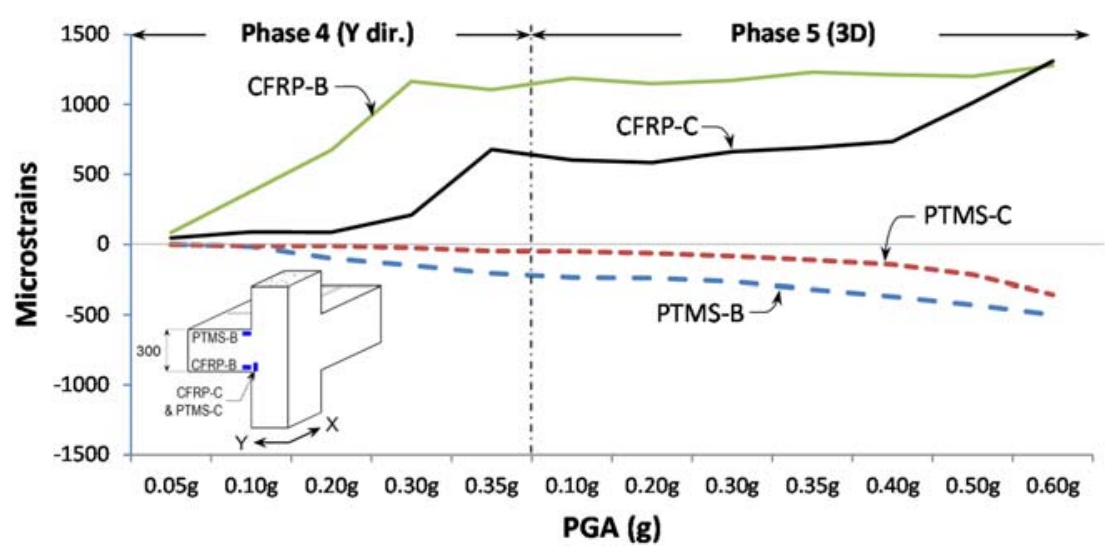

Fig. 19 Accumulated residual strains in CFRP sheets and metal straps 

effective at enhancing the capacity of substandard RC buildings likely to experience large interstorey drift ratio demands (i.e. close to a CP performance level). Due to the low material costs and ease of installation, the PTMS technique is especially suitable for retrofitting structures, particularly in developing countries. However, the minor damage observed in some of the push type metal seals and bolts at high levels of PGA indicates that further research is necessary to develop more efficient anchorage systems.

\section{Conclusions}

This article examined the effectiveness of CFRP and PTMS retrofitting solutions through full-scale shaking table tests on a substandard RC building. Based on the experimental results, the following conclusions are drawn:

1) The initial tests on the original substandard building were halted at a $P G A=0.15 \mathrm{~g}$ to avoid a possible collapse caused by the premature local failure of the beam-column joints at the $2^{\text {nd }}$ floor.

2) After significant damage, the local repairs (i.e. crack injection and concrete patching) and dual CFRP/PTMS retrofitting of columns and joints were effective at restoring the lateral stiffness of the building by $75 \%$.

3) Whilst the $2^{\text {nd }}$ floor of the original bare structure reached a critical level of damage at PGA $=0.15 \mathrm{~g}$, the CFRP/PTMS-retrofitted building sustained 3D seismic shaking up to a much higher PGA $=0.60 \mathrm{~g}$ without compromising its stability. The proposed CFRP/PTMS retrofitting intervention also led to a more uniform damage distribution and, therefore, to a better exploitation of the available capacity in the structure.

4) In comparison to the original bare building, the retrofitting intervention enhanced the interstorey drift ratio capacity of the $1^{\text {st }}$ and $2^{\text {nd }}$ floors by $160 \%$ and $110 \%$, respectively. The building remained safely within the Collapse Prevention performance level and without evidence of potential collapse.

5) Although some push type seals sheared off during the tests at high PGA levels (Phase 5), the metal straps maintained $70-80 \%$ of their initial post-tensioning force, thus confirming the reliability of the PTMS technique 

adopted retrofitting solution also led to a strong column-weak beam behaviour and yielding of the beams at the $1^{\text {st }}$ floor, which is in line with current seismic design philosophy. It can be concluded that both CFRP and PTMS retrofitting systems are extremely effective at enhancing the performance of substandard RC structures, and are suitable for retrofitting existing buildings exposed to high seismic hazard. While this article mainly focused on the effectiveness of external reinforcement on exterior joints and columns, the application of the proposed CFRP and PTMS retrofitting systems may be challenging for interior joints. To address this issue, several FRP retrofitting and anchoring solutions are commercially available for interior/exterior columns and joints. The proposed detailing for PTMS strengthening of exterior joints can be also adopted for interior joints; however, more efficient PTMS anchoring solutions could be developed in future research. Further research should also investigate the effectiveness of the anchoring system for the flexural straps on low-strength concrete, where the anchoring bolts may cause damage to the surrounding concrete.

\section{References}

AFNOR (2007) Aciers pour beton arrne - Aciers soudables a verrous Partie1: Barres et couronnes. NF A 35-016-1, Association Française de Normalisation, Paris

Akguzel U, Pampanin S (2010) Effects of variation of axial load and bidirectional loading on seismic performance of GFRP retrofitted reinforced concrete exterior beam-column joints. J Compos Constr 14 (1):94-104. doi:10.1061/(Asce)1090-0268(2010)14:1(94)

Al-Salloum YA, Almusallam TH, Alsayed SH, Siddiqui NA (2011) Seismic behavior of as-built, ACI-complying, and CFRP-repaired exterior RC beam-column joints. J Compos Constr 15 (4):522-534. doi:10.1061/(Asce)Cc.19435614.0000186

Antonopoulos CP, Triantafillou TC (2003) Experimental investigation of FRP-strengthened RC beam-column joints. J Compos Constr 7 (1):39-49. doi:10.1061/(Asce)1090-0268(2003)7:1(39)

ASCE (2007) ASCE/SEI 41-06 Seismic rehabilitation of existing buildings. American Society of Civil Engineers, Reston, VA

Biddah A, Ghobarah A, Aziz TS (1997) Upgrading of nonductile reinforced concrete frame connections. J Struct Eng 123 (8):1001-1010

CEN (2004a) EN 1992-1-1:2004. Eurocode 2: Design of concrete structures, Part 1-1: General rules and rules for buildings. Comité Européen de Normalisation, Lausanne

CEN (2004b) EN 1998-1:2004 Eurocode 8 - Design of structures for earthquake resistance Part 1: General rules, seismic actions and rules for buildings. Comité Européen de Normalisation, Lausanne

CEN (2009a) EN 12390-5:2009 Testing hardened concrete Part 5: Flexural strength of test specimens. Comité Européen de Normalisation. Lausanne, Switzerland 
CEN (2009b) EN 12390-6:2009 Testing hardened concrete Part 6: Tensile splitting strength of test specimens. Comité Européen de Normalisation,. Lausanne, Switzerland

Clough RW, Penzien J (2003) Dynamics of structures. Computers \& Structures, Inc, Berkeley, CA

Corazao M, Durrani AJ (1989) Repair and strengthening of beam-to-column connections subjected to earthquake loading. National Center for Earthquake Engineering Research, State University of New York at Buffalo,

DiPasquale E, Ju JW, Askar A, Cakmak AS (1990) Relation between global damage indexes and local Stiffness degradation. J Struct Eng-Asce 116 (5):1440-1456. doi:10.1061/(Asce)0733-9445(1990)116:5(1440)

Frangou M (1996) Strengthening of concrete by lateral confinement. Ph.D. thesis, Dept. of Civil and Structural Engineering, The University of Sheffield, UK

Frangou M, Pilakoutas K, Dritsos S (1995) Structural repair strengthening of RC columns. Cons Build Mater 9 (5):259266. doi:10.1016/0950-0618(95)00013-6

Garcia R, Hajirasouliha I, Guadagnini M, Helal Y, Jemaa Y, Pilakoutas K, Mongabure P, Chrysostomou C, Kyriakides N, Ilki A, Budescu M, Taranu N, Ciupala MA, Torres L, Saiidi M (2014a) Full-scale shaking table tests on a substandard RC building repaired and strengthened with Post-Tensioned Metal Straps. Journal of Earthquake Engineering 18 (2): 187-213. doi:10.1080/13632469.2013.847874

Garcia R, Hajirasouliha I, Pilakoutas K (2010) Seismic behaviour of deficient RC frames strengthened with CFRP composites. Eng Struct 32 (10):3075-3085. doi:10.1016/j.engstruct.2010.05.026

Garcia R, Helal Y, Pilakoutas K, Guadagnini M (2014b) Bond behaviour of substandard splices in RC beams externally confined with CFRP. Construction and Building Materials 50:340-351

Garcia R, Helal Y, Pilakoutas K, Guadagnini M (2015) Bond strength of short lap splices in RC beams confined with steel stirrups or external CFRP. Materials and Structures 48 (1-2):277-293. doi:10.1617/s11527-013-0183-5

Garcia R, Jemaa Y, Helal Y, Guadagnini M, Pilakoutas K (2014c) Seismic strengthening of severely damaged beamcolumn RC joints using CFRP. J Compos Constr 18 (2). doi:10.1061/(Asce)Cc.1943-5614.0000448

Gdoutos EE, Pilakoutas K, Rodopoulos CA (2000) Failure analysis of industrial composite materials. McGraw-Hill New York,

Ghobarah A, Aziz TS, Biddah A (1996) Seismic rehabilitation of reinforced concrete beam-column connections. Earthquake Spectra 12 (4):761-780. doi:10.1193/1.1585909

Ghobarah A, El-Amoury T (2005) Seismic rehabilitation of deficient exterior concrete frame joints. J Compos Constr 9 (5):408-416. doi:10.1061/(Asce)1090-0268(2005)9:5(408)

Hajirasouliha I, Asadi P, Pilakoutas K (2012) An efficient performance-based seismic design method for reinforced concrete frames. Earthq Eng Struct D 41 (4):663-679. doi:10.1002/Eqe.1150

Helal Y (2012) Seismic strengthening of deficient RC elements using PTMS. Ph.D. thesis, Dept. of Civil and Structural Engineering, The University of Sheffield, UK

Helal Y, Garcia R, Guadagnini M, Pilakoutas K, Hajirasouliha I (2014) Strengthening of short splices in RC beams using post-tensioned metal straps. Materials and Structures - (-):1-15. doi:10.1617/s11527-014-0481-6

Ilki A, Bedirhanoglu I, Kumbasar N (2011) Behavior of FRP-retrofitted joints built with plain bars and low-strength concrete. J Compos Constr 15 (3):312-326. doi:10.1061/(ASCE)CC.1943-5614.0000156

Karayannis CG, Chalioris CE, Sirkelis GM (2008) Local retrofit of exterior RC beam-column joints using thin RC jackets - An experimental study. Earthq Eng Struct Dyn 37 (5):727-746. doi:10.1002/Eqe.783

Kyriakides N, Ahmad S, Pilakoutas K, Neocleous K, Chrysostomou C (2014) A probabilistic analytical seismic vulnerability assessment framework for substandard structures in developing countries. Earthq Struct 6 (6):665687

Li JB, Gong JX, Wang LC (2009) Seismic behavior of corrosion-damaged reinforced concrete columns strengthened using combined carbon fiber-reinforced polymer and steel jacket. Cons Build Mater 23 (7):2653-2663. doi:10.1016/j.conbuildmat.2009.01.003

Ministry of Construction of China (2001) Code for seismic design of buildings (GB50011-2001). China Architecture and Building Press, Beijing

Moghaddam H, Samadi M, Pilakoutas K, Mohebbi S (2010) Axial compressive behavior of concrete actively confined by metal strips; part A: experimental study. Mater Struct 43 (10):1369-1381. doi:10.1617/s11527-010-9588-6

Mongabure P (2012) BANDIT project: seismic tests on a reinforced concrete frame with post-tensioned metal strips retrofitting, final report. FP7 SERIES Programme (Seismic Engineering Research Infrastructures for European Synergies).

Pantelides CP, Gergely J (2008) Seismic retrofit of reinforced concrete beam column T-joints in bridge piers with FRP composite jackets. Paper presented at the SP-258: Seismic Strengthening of Concrete Buildings Using FRP Composites (in CD-ROM),

Parvin A, Altay S, Yalcin C, Kaya O (2010) CFRP rehabilitation of concrete frame joints with inadequate shear and anchorage details. J Compos Constr 14 (1):72-82. doi:10.1061/(Asce)Cc.1943-5614.0000055 
RILEM (1994) RILEM Recommendations for the testing and use of constructions materials - CPC 8 modulus of elasticity of concrete in compression 1975. Seismic retrofitting of nonductile beam-column sub-assemblage using FRP wrapping and steel plate jacketing. Cons Build Mater 25 (1):175-182. doi:10.1016/j.conbuildmat.2010.06.041

Sezen H (2012) Repair and strengthening of reinforced concrete beam-column joints with Fiber-Reinforced Polymer Composites. J Compos Constr 16 (5):499-506. doi:10.1061/(Asce)Cc.1943-5614.0000290 Eng Struct D 40 (3):293-313. doi:10.1002/Eqe.1028

Tsonos ADG (2010) Performance enhancement of R/C building columns and beam-column joints through shotcrete jacketing. Eng Struct 32 (3):726-740. doi:10.1016/j.engstruct.2009.12.001

Zembaty Z, Kowalski M, Pospisil S (2006) Dynamic identification of a reinforced concrete frame in progressive states of damage. Eng Struct 28 (5):668-681. doi:10.1016/j.engstruct.2005.09.025 